\title{
Torsion-shear behaviour at the interfaces of rigid interlocking blocks in masonry assemblages. Experimental investigation and analytical approaches
}

Claudia Casapulla ( $\sim$ claudia.casapulla@unina.it)

University of Naples Federico II: Universita degli Studi di Napoli Federico II https://orcid.org/0000-0002-

8734-947X

Elham Mousavian

University of Naples Federico II: Universita degli Studi di Napoli Federico II

Luca Argiento

University of Naples Federico II: Universita degli Studi di Napoli Federico II

Carla Ceraldi

University of Naples Federico II: Universita degli Studi di Napoli Federico II

Katalin Bagi

Budapest University of Technology and Economics: Budapesti Muszaki es Gazdasagtudomanyi

Egyetem

\section{Research Article}

Keywords: 3D locks, Torsion capacity, Experimental yield domains, Limit analysis, Discrete Element Method (3DEC), Convexity formulation, Concavity formulation

Posted Date: May 12th, 2021

DOI: https://doi.org/10.21203/rs.3.rs-296134/v1

License: (c) (i) This work is licensed under a Creative Commons Attribution 4.0 International License.

Read Full License 


\title{
Torsion-shear behaviour at the interfaces of rigid interlocking blocks in masonry assemblages. Experimental investigation and analytical approaches
}

\author{
Claudia Casapulla $^{1 *}$, Elham Mousavian $^{1}$, Luca Argiento $^{1}$, Carla Ceraldi $^{1}$, Katalin Bagi $^{2}$ \\ ${ }^{1}$ Department of Structures for Engineering and Architecture, University of Naples Federico II, Italy \\ claudia.casapulla@unina.it,elham.mousavian@unina.it, lucaumberto.argiento@unina.it,carla.ceraldi@unina.it
}

${ }^{2}$ Department of Structural Mechanics, Budapest University of Technology and Economics, Hungary bagi.katalin@emk.bme.hu

\begin{abstract}
Increasing interest has recently been devoted to interlocking blocks/interfaces capable to enhance the sliding resistance of masonry joints to external forces. In this framework, this paper deals with the assessment of the torsion-shear capacity of the contact interface between the lock and the main body of an interlocking block, assumed to have a cohesive behaviour. The interlocking block is a rigid unit which, on its faces, have locks keeping the adjacent/overlapped blocks together and preventing blocks from sliding. Two numerical approaches and a novel ad hoc experimental investigation are proposed to simulate the torsion-shear behaviour by applying eccentrical shear forces to the lock. First, concave, convex and corrected concave formulations provided by the literature for assemblages of rigid blocks with conventional planar joints are extended to model the interlocking block behaviour. Then, according to a second approach based on the discrete element method, the concave-shaped interlocking block is modelled by convex polyhedrons representing the lock and the main body of the block, considered as individual rigid units stacked over each other with a cohesive contact in between. A novel experimental investigation on the limiting pure shear and torsion-shear combinations at the lock interface made of cohesive material is also presented. Two different mortars were chosen to make the specimens, which were casted using 3D printed moulds, and different test configurations were set up to simulate shear and torsion-shear failures. The analytical and numerical results are compared with each other and against the experimental ones, with interesting remarks on the application of the different approaches.
\end{abstract}

KEYWORDS: 3D locks, Torsion capacity, Experimental yield domains, Limit analysis, Discrete Element Method (3DEC), Convexity formulation, Concavity formulation.

\section{Introduction}


Throughout the entire history of building construction, masonry has been one of the most common and efficient techniques, due to the simple geometry of units, their affordability, and great structural properties. The discontinuous and non-homogenous nature of the constitutive elements of masonry, i.e. units and mortar, strongly affects the in-plane and out-of-plane behaviour of masonry walls under various external loading. In traditional masonry block structures subjected to seismic loading, the joints between units act as planes of weakness due to their low tensile and shear bond strength, while the use of non-planar interlocking joints is recently becoming very popular to improve the mechanical behaviour at block interfaces.

The interface behaviour of traditional masonry planar joints has widely been studied with advanced non-linear computational formulations, mostly based on the homogenized finite element analysis (FEA) at the micro-scale level, detailing blocks, mortar and the block/mortar interface [1]. As an alternative, the assessment of discontinuous media composed of discrete bodies and contacts in between has increasingly been investigated using the discrete element method (DEM) first developed by Cundall [2]. This approach, specifically its version based on an explicit time integration method $[2,3]$, is the core of the software 3DEC [4], suitable to model 3D masonry systems as assemblages of deformable or rigid blocks with contacts representing dry or mortar joints [5-12]. The greatest advantage of DEM compared with FEA is its capability to simulate the large displacements between the bodies as well as sliding and partial or complete separation of neighbouring blocks. However, both FEA and DEM require high computational cost and advanced operational knowledge to properly define material properties, discretization, boundary conditions, input parameters, etc., which make them less convenient for everyday engineering professional applications.

Less demanding methods in terms of computational effort and accurate knowledge of state characteristics are those based on limit analysis procedures, assuming the masonry structure as an assemblage of rigid blocks and contact interfaces, with infinitive or finite friction [13]. The yield domains in terms of ultimate shear, torsion-shear and torsion-shear-bending moment interactions at joints are taken into account using convex and concave formulations [13-15], and experimental results carried out on 3D dry-stacked units [16, 17]. For these simplified methods, several contributions were recently proposed to assess the seismic vulnerability of masonry buildings [18, 19].

On the other hand, increasing interest has recently been devoted to interlocking blocks capable to enhance the sliding resistance of masonry joints. These blocks are rigid units which, on their faces, have locks keeping the blocks together, preventing them from sliding. Experimental and numerical tests [20], investigated the in-plane and out-of-plane capacity of masonry walls composed of blocks with corrugated interfaces. Out-of-plane behaviour of osteomorphic blocks and interfaces with cross shaped locks were also experimentally investigated by Dyskin et al. [21] and Ali et al. [22], 
respectively. Similarly, experimental and numerical investigations were carried out on the different behaviour of wooden joinery connections with different geometric properties [23-26]. A digital tool to design structurally feasible masonry structures composed of interlocking blocks has been developed by some of the presenting authors [27-29].

One of the key factors influencing the behaviour of the conventional mortared block masonry is the bond strength between the mortar and the units, which also affects the pull-out strength of injected anchors frequently used in masonry walls [30]. Similarly, the shear strength between the lock and the main body of the interlocking block is of utmost importance for dry masonry with interlocking interfaces. This means that, if interlocking blocks are composed of cohesive material at their interfaces, the Mohr-Coulomb criterion can be adopted for both systems, for which the bond strength itself depends on the initial shear strength (cohesion) and the coefficient of friction, as well as the level of normal stresses. To determine the initial shear strength and the coefficient of friction, only European Standard EN 1052-3 [31] test method is available so far. However, the scientific literature shows that different domestic test methods have been developed worldwide, indicating the difficulty of finding a general consensus [32].

This paper is particularly focused on the assessment of the torsion-shear capacity of the contact interface between the lock and the main body of an interlocking block, assumed to have a cohesive behaviour. To this aim, two numerical approaches and a novel ad hoc experimental investigation are herein proposed to simulate this behaviour by applying eccentrical shear forces to the upper lock.

The paper is organised as follows. In Section 2, the analytical formulations of the concave, convex and corrected concave models proposed by Casapulla and Maione [14] are extended to such an interface, considering the shear resistance different from the frictional resistance. Section 3 explores the DEM capability to model interlocking joints for the simplest case study of an interlocking cuboidal block with a cuboidal lock on its main body. A novel test method is then proposed in Section 4 to evaluate the initial shear and torsion-shear capacity of a single lock of an interlocking block. The test setup is similar to that used for dry-stacked tuff blocks [16], but with different load applications and constraints, to allow the absence of normal force on the cohesive interface between the two parts of the block (lock and main body) kept rigid during the tests. Section 5 presents the comparison of the analytical and numerical results against the experimental ones, with interesting remarks on the application of the different approaches. Finally, the conclusions are summarized in Section 6.

\section{Analytical contact formulations for torsion-shear interactions in limiting conditions}

An assemblage of interlocking blocks can be modelled as a set of units with potential failure surfaces at their inner sides and boundaries. For an interlocking block represented in Figure 1a, its main body 
and locks (projections keeping the blocks together) can be considered rigid enough, so that the failure surfaces are assumed to be the dry joints between two blocks (blue planes), with potential sliding along the locks, together with the fracture planes at which each block might crack (red planes). The assumption of rigid bodies for the main body and the locks becomes even more reliable as the number of locks is increased; therefore, the key issue is to define the load-bearing capacity of each lock connection.

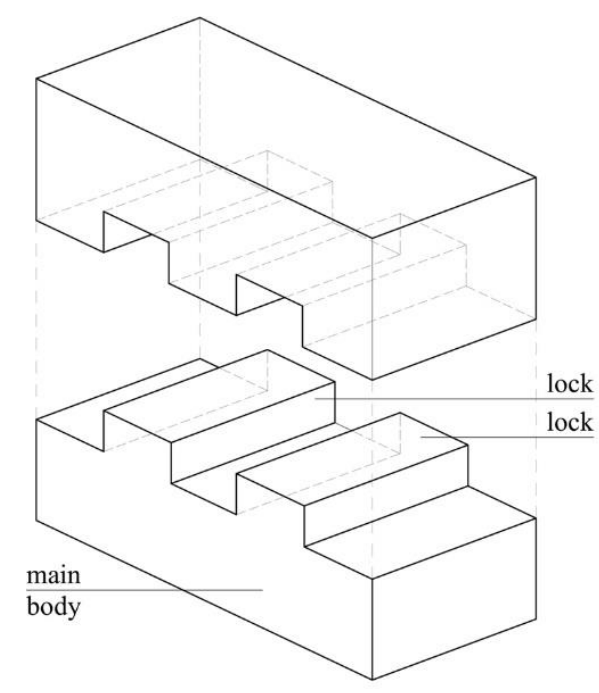

(a)

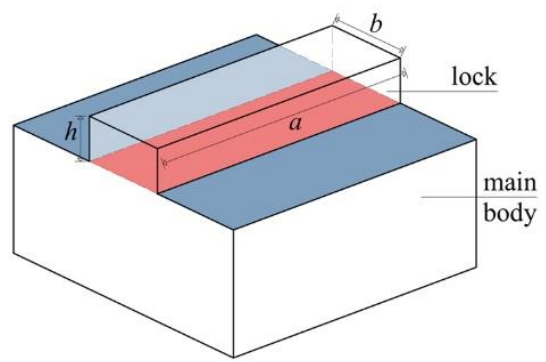

(b)

Figure 1. 3D representation of an interlocking block with (a) three locks and (b) only one lock.

Basically, a lock connection can be cracked due to bending or torsion-shear failure when the lock is subjected to lateral forces. Considering a sufficiently thick lock to avoid its bending failure [27], the cracking at the interface with the main body may occur for different combinations of torsion moment and shear force.

The main objective of this paper is to investigate these yield conditions at the single lock connection (Figure 1b), which is carried out using different idealizations of the contact interfaces (listed above), among which the convexity and the concavity models are the most common ones [13]. These models are generally used for the dry contact interfaces between masonry blocks, governed by the cohesionless Coulomb's law of friction, to predict the limiting forces at the interface, though providing some discrepancy in the evaluation of the torsion capacity [33]. The related analytical formulations have recently been validated by comparison of the results with the experimental investigation carried out by Casapulla and Portioli [16], based on an ad hoc setup of two dry-stacked tuff stones. A reliable corrected concave formulation has then been developed to account for the discrepancy in the torsion capacity [14]. 
However, to apply these models to the lock connections, a shear resistance different from the frictional resistance should be defined. The following sections will address the extension of these two formulations to the lock connection, together with the assumed interface law.

\subsection{Convex and concave formulations}

The concave or point contact formulation is a dominant approach to model stress state of assemblages of rigid blocks, first developed by Livesley [13]. In this method, the contact interfaces are idealized so that the internal forces are distributed on a few contact points, usually located at the vertices of the contact interfaces. The stress resultant vector at each point has only a normal and a shear component, while the torsion capacity of the interface is represented by two couples of shear forces orthogonal to the interface diagonals. Moreover, different twisting centres are possible for uniform and non-uniform distributions of shear components and normal forces.

Instead, the convex contact formulation represents the interaction between two blocks via the stress state at a single point on their interface [13]. The stress resultant vector at this point includes six components of normal and shear forces as well as bending and torsion moments. It is worth noting that, although this formulation implies that the contact occurs at a single point, as if the two surfaces in contact were slightly convex, the shear, bending and torsion components imply their interactions along the entire surfaces [16].

To apply these formulations to the contact interface between the main body and the lock of an interlocking block, first the shear resistance of the interface should be introduced. In the case of cohesive-frictional material at this interface, the Mohr-Coulomb law may be used, which considers the shear resistance of a lock subjected to shear and compressive forces to be greater than the shear resistance of a lock only subjected to pure shear forces, because of the effect of the compression. However, for the sake of safety and to make the shear resistance independent of the normal force, the Tresca yield criterion [27, 34] is assumed and the pure shear resistance, e.g. due to cohesion, is considered as the limiting value, neglecting the contribution of the compressive forces. This means that the limiting pure shear force for the lock interface is (Figure 1b):

$$
V_{0}=\tau_{0} a b
$$

where $\tau_{0}$ is the cohesion or the pure shear strength depending on the material properties. Based on the so defined pure shear resistance, the two formulations for torsion-shear interaction previously developed for dry contact interfaces in [14] can easily be applied to the lock interface, as summarised in the following. 
The interaction effect of the torsion moment $M_{\mathrm{T}}$ and the shear force $V\left(V_{x}, V_{y}\right)$ occurs when the shear force is applied to the lock with some eccentricity $e\left(e_{x}, e_{y}\right)$ with respect to the centroid $\mathrm{O}$ of the contact interface (Figure 2a,b) so that $M_{\mathrm{T}}=V_{x} e_{y}+V_{y} e_{x}$. In this case, using the superimposed symbols $\wedge$ and $\vee$ to denote convexity and concavity, respectively, the convexity model (Figure $2 \mathrm{a}$ ) provides highly non-linear relationships among the variables $\widehat{V}_{x}, \widehat{V}_{y}, \widehat{M}_{T}$ and the coordinates of the torsion centre $\mathrm{T}\left(x_{T}, y_{T}\right)$, as described by Casapulla [35]. In particular, when $\widehat{V}_{x}=0$ (torsion centre on $X$-axis), still assuming that the shear stress at each point of the interface is orthogonal to a line connecting the point and $\mathrm{T}$, the torsion-shear interaction is described by the following equilibrium equations (Figure 2c):

$\widehat{V}_{y}=\widehat{V}=\frac{V_{0}}{4 a b}\left[b(A-B)+2\left(x_{T}+a\right)^{2} \ln \frac{b+A}{-b+A}+2 x_{T}^{2} \ln \frac{-b+B}{b+B}\right]$

$\widehat{M}_{T}=\frac{V_{0}}{6 a b}\left[-x_{T} b B+\left(x_{T}+a\right) b A+x_{T}^{3} \ln \frac{-b+B}{b+B}+\left(x_{T}+a\right)^{3} \ln \frac{b+A}{-b+A}-\frac{b^{3}}{4} \ln \frac{2 x_{T}+B}{2\left(x_{T}+a\right)+A}\right]+$

$-\widehat{V}_{y}\left(x_{T}+\frac{a}{2}\right)$

where:

$A=\sqrt{4\left(x_{T}+a\right)^{2}+b^{2}} ; \quad B=\sqrt{4 x_{T}^{2}+b^{2}}$

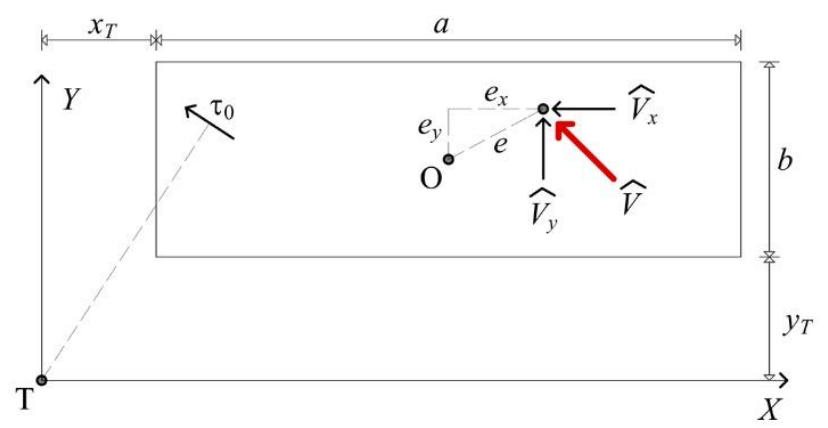

(a)

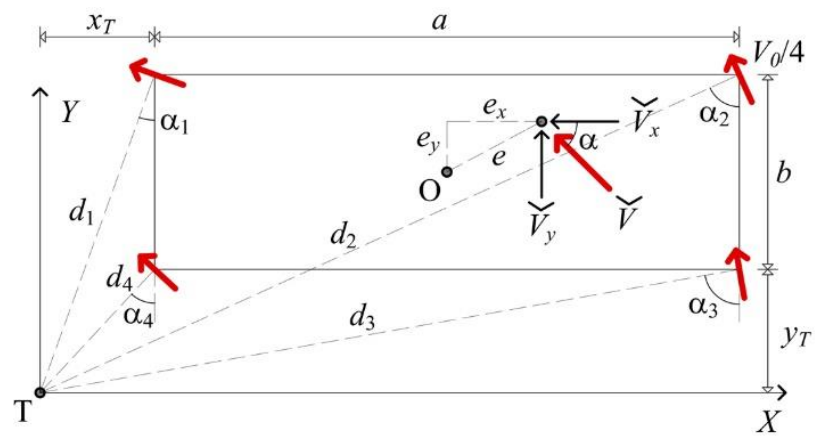

(b)

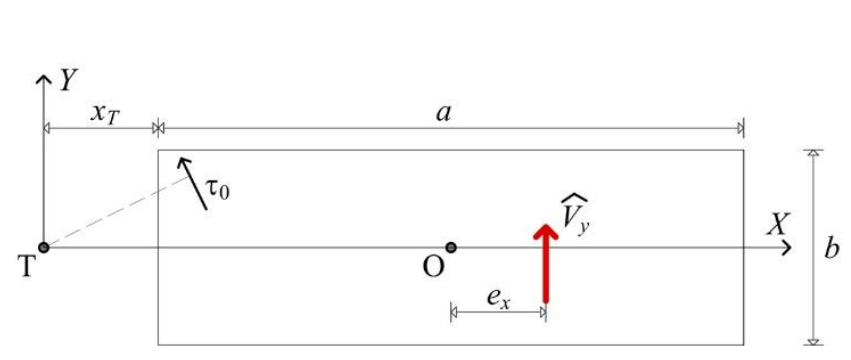

(c)

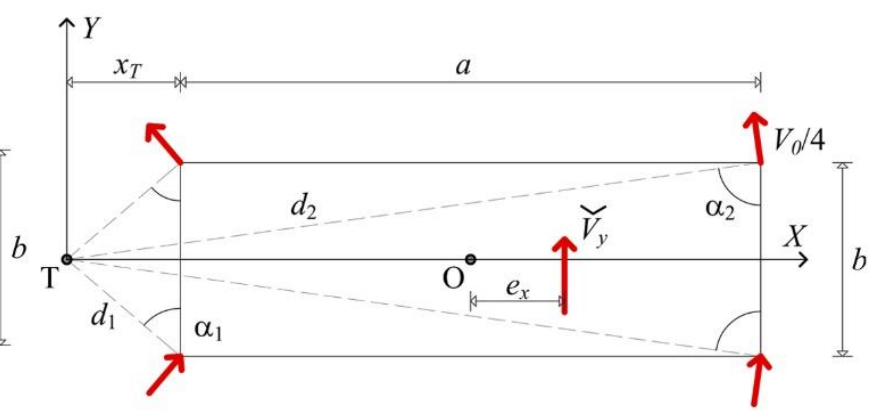

(d)

Figure 2. Torsion-shear interaction by the $(\mathrm{a}, \mathrm{c})$ convex and $(\mathrm{b}, \mathrm{d})$ concave contact interfaces. 
Like the convexity model, the concavity model also assumes that the shear strengths at the contact points are orthogonal to the lines connecting them to T, but these strengths are concentrated in four vertices whose distances from $\mathrm{T}$ are denoted as $d_{i}$, with $i=1$ to 4 (Figure 2b). Assuming again $\breve{V}_{x}=$ 0 , the torsion centre is on $X$-axis and the following relations can be derived depending on the block dimensions (Figure 2d):

$\breve{V}_{y}=\breve{V}=\frac{V_{0}}{2}\left(\sin \alpha_{1}+\sin \alpha_{2}\right)$

$\breve{M}_{T}=\left[\frac{b^{2}\left(d_{1}+d_{2}\right)+4 d_{1} a\left(a+x_{T}\right)}{8 d_{1} d_{2}}\right] V_{0}-\frac{a}{2} \breve{V}$

where:

$d_{1}=\sqrt{x_{T}^{2}+\left(\frac{b}{2}\right)^{2}} ; \quad d_{2}=\sqrt{\left(x_{T}+a\right)^{2}+\left(\frac{b}{2}\right)^{2}}$

A family of interaction curves can numerically be obtained for both formulations, for different aspect ratios $a / b$. However, the results obtained by the two models are not coincident with each other, and their difference increases with the prevalence of the torsion moment, as highlighted in [14]. In that paper, it was also demonstrated how this difference is related to the overestimation of the pure torsion capacity in the concavity model, and therefore a "corrected" concave formulation was proposed. This can also be applied to the lock connection, as developed in the following.

\subsection{Corrected concave formulation}

As remarked in the previous section, the torsion and torsion-shear yield domains obtained by the concave formulation appear to be less reliable in comparison with those obtained by the convex formulation, but the former allows enhancing the computational efficiency when it is used in micromodelling approaches for limit analysis of masonry walls [13].

To benefit from this advantage, the efficient correction of the torsion capacity proposed by Casapulla and Maione [14] is herein applied to the lock connection of the interlocking block (Figure 1b), with its direct effects on the torsion-shear interaction. It is based on finding the corrected positions of the contact points in the concave model that provide the pure torsion capacity equal to the convex formulation (Figure 3a). In fact, from the equation:

$\widehat{M}_{T 0}=V_{0} c_{T}=\breve{M}_{T 0}=V_{0} c_{1}$

it is derived that the position $c_{1}$ of the single contact point in Figure $3 \mathrm{~b}$ will be: 
$c_{1}=c_{T}=\frac{1}{12 a b}\left(a^{3} \ln \frac{b+d}{a}+b^{3} \ln \frac{a+d}{b}+2 a b d\right)$

where $d=\sqrt{a^{2}+b^{2}}$ is the length of the diagonals.

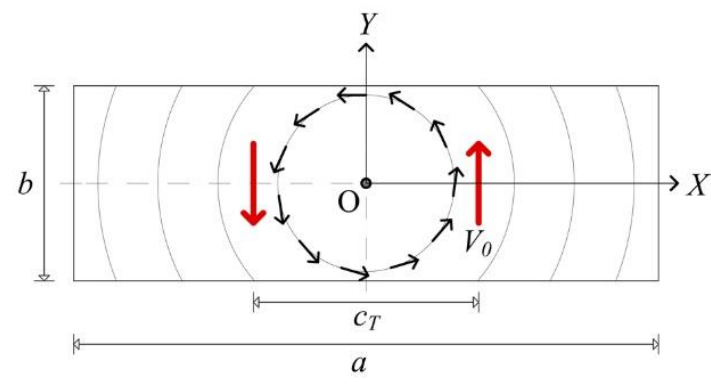

(a)

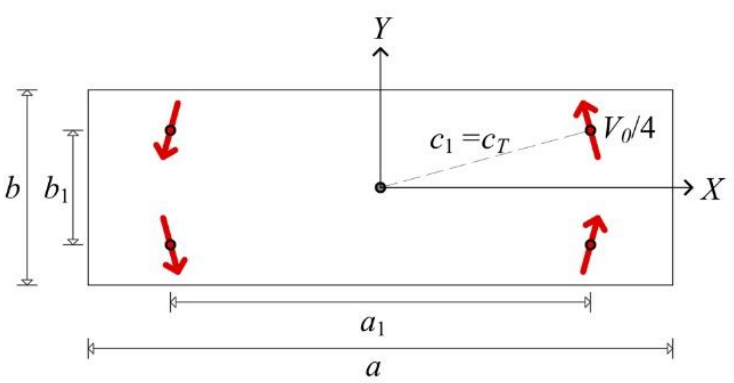

(b)

Figure 3. Shear stresses and/or forces over the (a) convex and (b) corrected concave contact interface under axial compression and pure torsion moment.

This means that a reduced effective area can be derived, with dimensions:

$a_{1}=\frac{c_{T}}{c} a ; \quad b_{1}=\frac{c_{T}}{c} b$

where $c$ is the actual half-diagonal, i.e. $c=d / 2$. Therefore, Eqs. (5) and (6) become:

$\breve{V}_{y}=\check{V}=\frac{V_{0}}{2}\left(\sin \alpha_{1}+\sin \alpha_{2}\right)$

$\breve{M}_{T}=\left[\frac{b_{1}^{2}\left(d_{1}+d_{2}\right)+4 d_{1} a_{1}\left(a_{1}+x_{T}\right)}{8 d_{1} d_{2}}\right] V_{0}-\frac{a_{1}}{2} \check{V}$

where $V_{0}, d_{1}$ and $d_{2}$ are derived by Eqs. (1) and (7), respectively, by replacing $a$ and $b$ with $a_{1}$ and $b_{1}$ in Eq. (10).

As will be shown in Section 5, this criterion also affects the torsion-shear interaction and can therefore be used as a potential yield domain for the lock connection.

\section{Numerical analysis for torsion-shear interactions in limiting conditions using discrete element modelling (3DEC)}

The torsion-shear capacity of the lock connection in Figure $1 \mathrm{~b}$ is herein also investigated using the discrete element approach by means of 3DEC [4], a 3D numerical modelling code for advanced analysis of discontinuous media subjected to either static or dynamic loading [2, 3].

Generally speaking, a concave-shaped element simulating the interlocking block in Figure 1b could be modelled in 3DEC by joining two convex polyhedrons, representing the lock and the main body (Figure 4a). However, to reproduce the torsion-shear behaviour at their interface better, these two 
convex polyhedrons are herein considered as individual rigid units stacked over each other with a cohesive contact in between (Figure $4 \mathrm{~b}$ ). Each of the rigid blocks is a body with three translational and three rotational degrees-of-freedom, while the deformable contact is discretized into finite elements, with three translational degrees of freedom at each vertex, based on the contact stressdisplacement law.

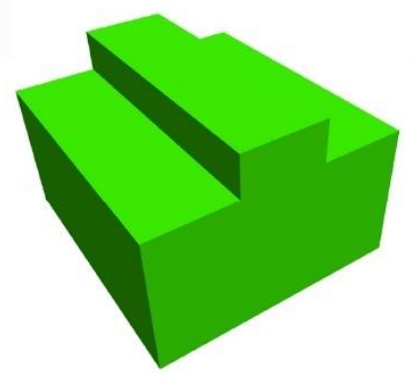

(a)

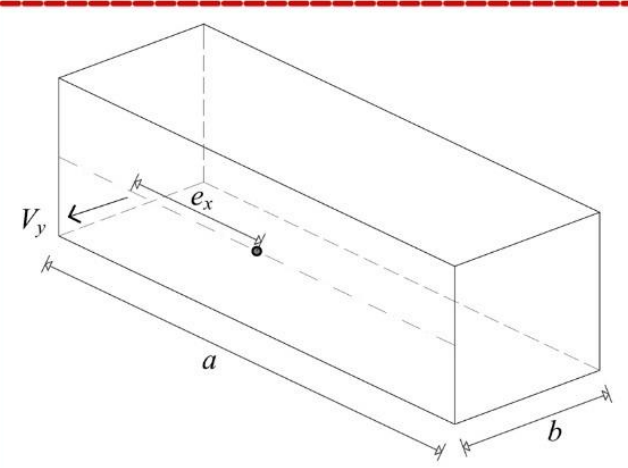

(c)

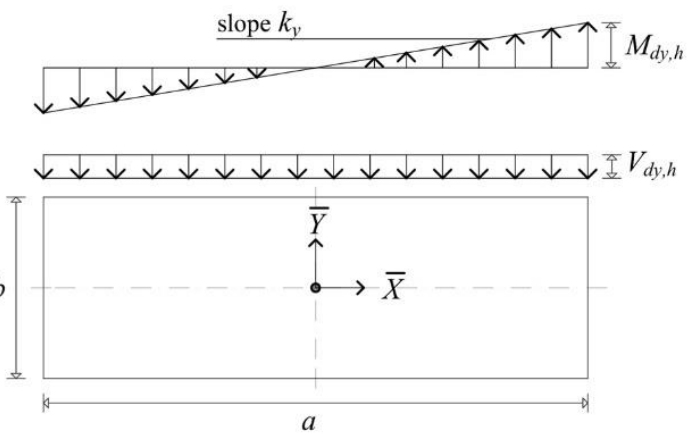

(e)

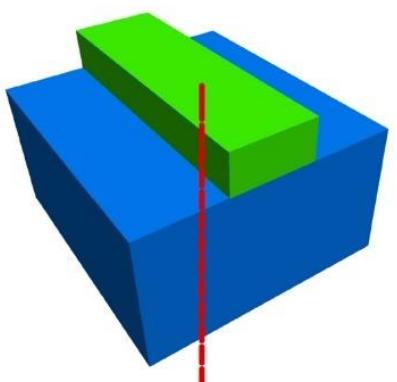

(b)

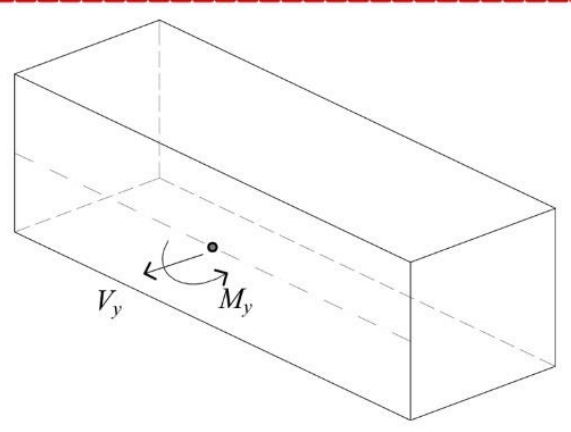

(d)

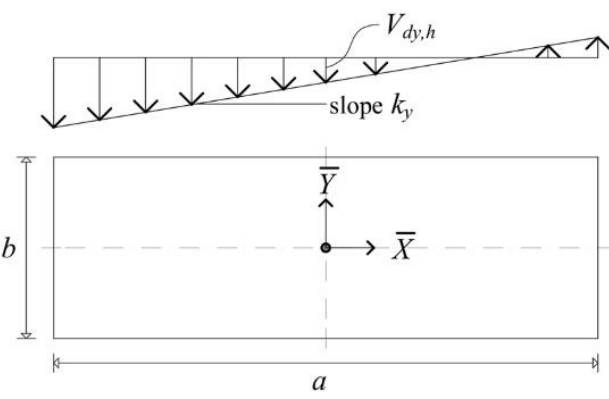

(f)

Figure 4. (a) Concaved shaped block modelled in 3DEC, (b) 3DEC Interlocking block modelled in this paper composed main body and lock with a cohesive contact, (c) to (f) replacing the pointed force normal to $X$ axis with a linearly distributed force.

Considering the interlocking block under study, high stiffnesses and Mohr-Coulomb criterion are assumed for the deformable interface between the two rigid parts (lock and main body). In particular, to approach the rigid-plastic behaviour assumed within the analytical formulations in Section 2, the normal and tangential stiffnesses of the contact interface can be considered equal to (or greater than) $10^{10} \mathrm{~N} / \mathrm{m}$, while to avoid the tensile failure at the same contact, the tensile strength is to be considered 
large enough, i.e. $10^{5} \mathrm{~N} / \mathrm{m}^{2}$. On the other hand, while the cohesion value is equal to the material shear strength, as applied in Section 5, to make the shear resistance independent of the normal stress (like the Tresca model), the contact friction angle is set to be zero.

To investigate the torsion-shear behaviour of the lock connection, the lower main body is fully fixed, while the upper lock is subjected to lateral point loads. These have different eccentricities with respect to the contact centroid to find the maximum load the contact can bear. Since applying point loads to the rigid block boundary is not possible in 3DEC, boundary stresses are instead applied as nonuniformly distributed forces, equivalent to a point load with some eccentricity.

Two directions of the point load are herein considered, including the lateral force normal to $X$ (Figure $4 \mathrm{c}$ ) and $45^{\circ}$ inclined with respect to this axis (Figure 5a).

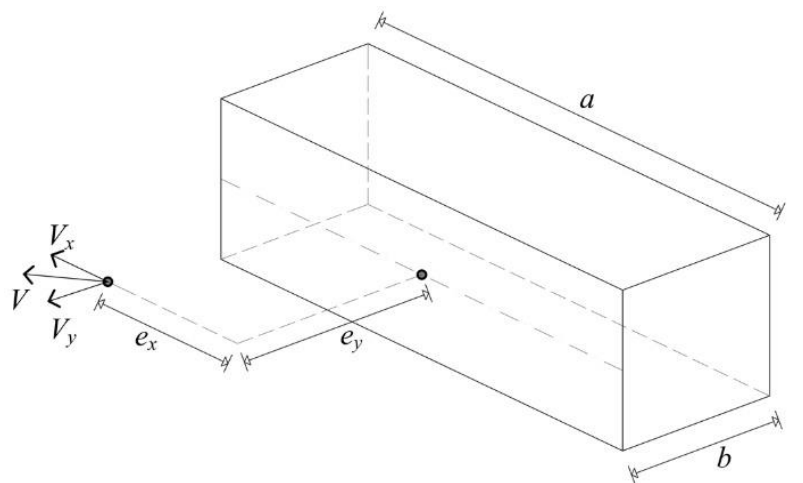

(a)

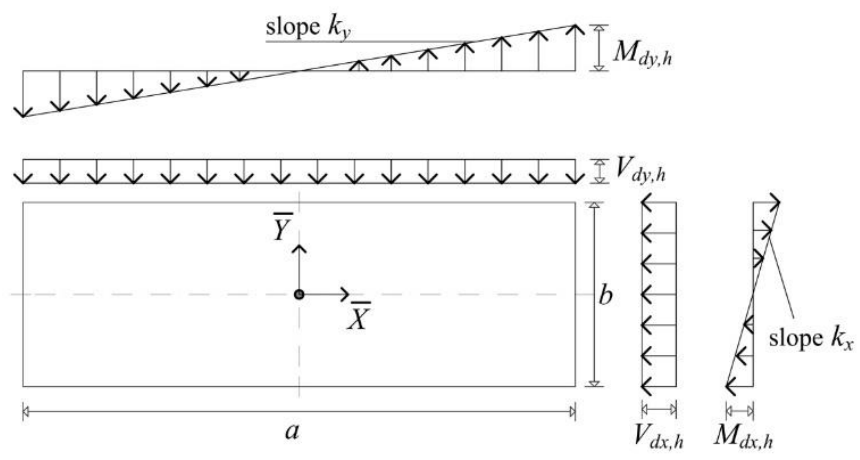

(c)

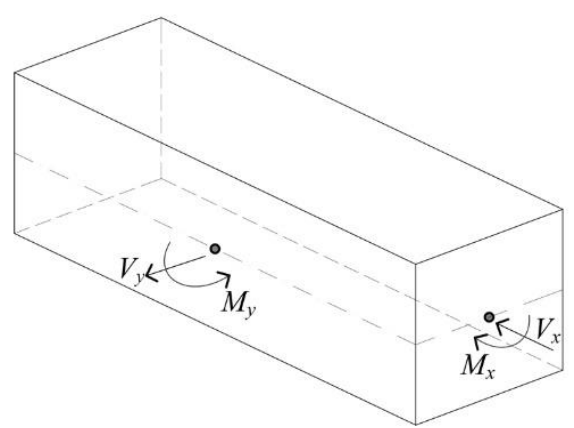

(b)

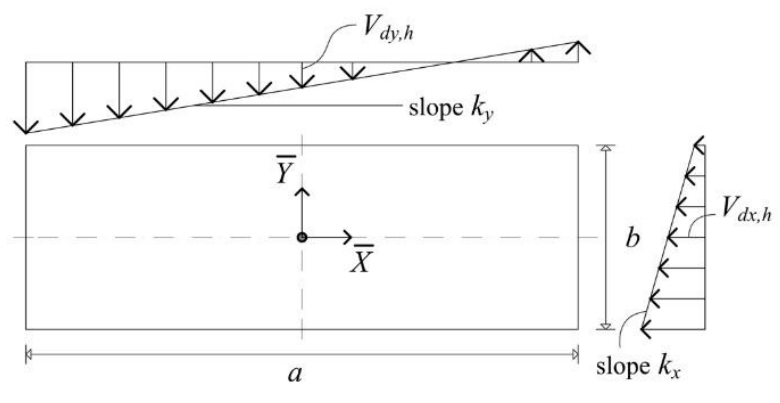

(d)

Figure 5. Replacing the pointed force $45^{\circ}$ inclined with respect to $X$ axis with two linearly distributed forces.

A force $V_{y}$ normal to the $X$ axis with eccentricity $e_{x}$ can be substituted by the same force and a torque $M_{y}=V_{y} e_{x}$ applied to the centroid of the vertical lock face (Figure 4d). Their distributions on the 2D lateral face of the lock (equal to $a h$ ) are displayed in Figure 4e, where:

$V_{d y, h}=\frac{V_{y}}{a h} ; \quad M_{d y, h}=\frac{6 M_{y}}{a^{2} h}$

and the slope $k_{y}$ of the linear distribution is: 
$k_{y}=\frac{12 M_{y}}{a^{3} h}$

On the other hand, an inclined force $V$ with eccentricity $e$ can be decomposed by two components normal to the $X$ and $Y$ axes, i.e. $V_{x}=V_{y}=\frac{\sqrt{2}}{2} V$ and $e_{x}=e_{y}=\frac{\sqrt{2}}{2} e$ (Figure 5a,b). The components of the force and torque in the two directions can be substituted by $\left\{V_{d y, h}, M_{d y, h}\right\}$ and $\left\{V_{d x, h}, M_{d x, h}\right\}$ (Figure 5c), respectively defined by Eq. (13) and by:

$V_{d x, h}=\frac{V_{x}}{b h} ; \quad M_{d x, h}=\frac{6 M_{x}}{b^{2} h}$

while the slope $k_{x}$ of the linear distribution is:

$k_{x}=\frac{12 M_{x}}{b^{3} h}$

Summing up each pair of the distributed forces representing $V$ and $M$, a linearly non-uniform distributed force is obtained (Figures $4 \mathrm{f}$ and $5 \mathrm{~d}$ ).

To study the torsion-shear behaviour of the cohesive contact, the ultimate normal and inclined $V$ are found for different eccentricities, by incrementally increasing $V$. The ultimate $V$ is in fact the maximum lateral force equilibrating the system. However, in the case of the pure shear condition, the shear stress at the interface multiplied by the contact area has turned out to be different from the applied $V$. This discrepancy occurs when the width of the lock is smaller than that of the main body, and to remedy this drawback, the main block has been divided into three fixed parts (Figure 6a). The shear and tensile strengths at the vertical contacts between them are considered very large to simulate they are part of a unique rigid block.

Furthermore, it has been observed that applying the non-uniformly distributed force on a rigid model, the shear stress distribution varies for different types of face triangulations. A contact can be discretised using different triangulation commands provided by 3DEC and the ideal commands are those who can discretize a contact symmetrically. Two of these commands are "radial" and "rad8", where the former adds a vertex on the face centroid, the latter adds vertices on the face centroid and on the middle of boundary edges (Figures $6 \mathrm{~b}-\mathrm{d}$ ).

Also, the contact can be discretised into smaller sub-contacts with more contact points through dividing and then joining the related polyhedrons. Figures $6 \mathrm{c}-\mathrm{e}$ show a cohesive interface divided into four pieces, triangulated using rad8, and joined again (divide-join rad8), respectively.

Difference in the shear stress distribution results in finding different ultimate force $V$, and the difference increases with the eccentricity. Later in Section 5 , the obtained ultimate $V$ found by these 
four face triangulation types are compared to those obtained by analytical and experimental investigations.

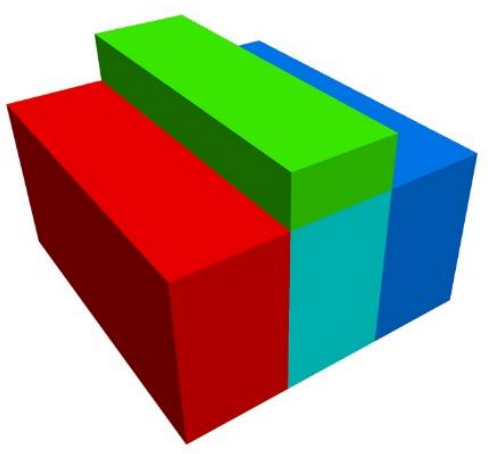

(a)

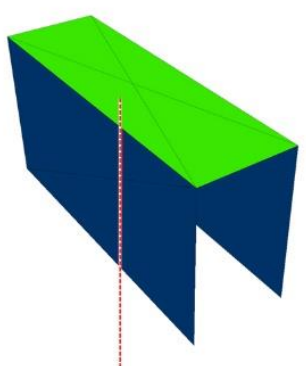

(b)

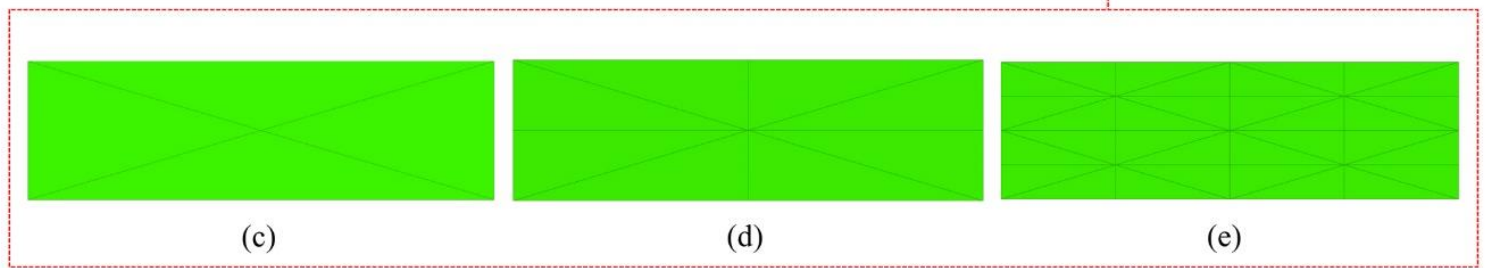

Figure 6. (a,b) Discretisation of the main body to remove the equilibration error; different face triangulation models for the contacts between rigid blocks as: (c) radial, (d) rad8 and (e) divide-join rad8.

\section{Experimental investigation on the lock under torsion-shear loading}

In this section, an experimental investigation on the limiting pure shear and torsion-shear combinations at the lock interface of a simple interlocking block made of cohesive material is presented. An ad hoc test setup was realized to estimate these resistances at the interface between the lock and the main body, while keeping them rigid.

Two different mortars were chosen to make the specimens, which were casted using 3D printed moulds, and four different test configurations (sets) were set up to simulate shear and torsion-shear failures. Combining the four sets and the two mortars, eight samples were tested. Two samples were tested in pure shear (each involving four specimens), while six samples were tested in torsion-shear condition (each involving three specimens), in total providing twenty-six experimental results.

The experimental investigation was carried out with standard and non-standard equipment at Laboratory of the Department of Structures for Engineering and Architecture (DiSt) of the University of Napoli Federico II (Italy).

\subsection{Specimen shape and characterization of two mortars}

The first phase of the experimental investigation focused on finding the proper shape and dimensions for the interlocking block and appropriate mechanical properties for the specimens made of cohesive material. 
The designed specimen is composed of a main body, which is a $100 \times 90 \times 50 \mathrm{~mm}^{3}$ cuboid, with a 100x30x15 $\mathrm{mm}^{3}$ cuboidal lock located on its upper face (Figure 7a). Before defining this final shape, several specimens were made by casting mortars with different mixtures in a mould (an ad hoc formwork to make the customized lock dimensions), and different moulds were also explored. The final formwork was composed of pieces provided in the desired shape and dimension by a 3D printer (Figure $7 b, c)$.

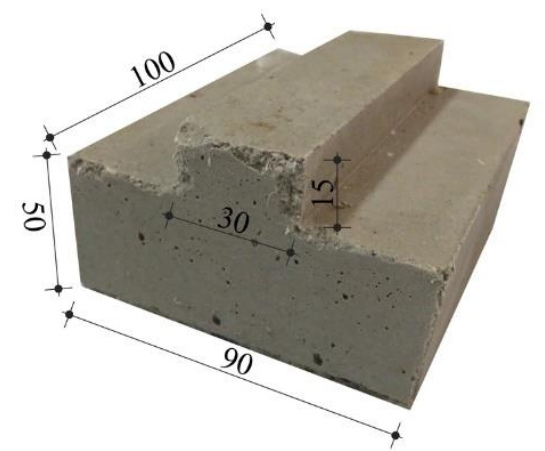

(a)

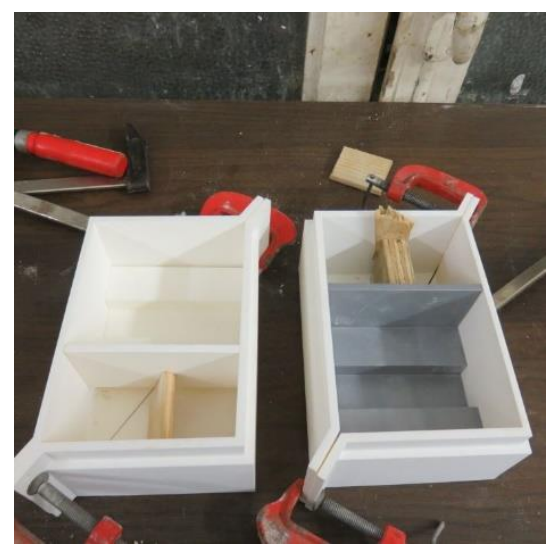

(c)

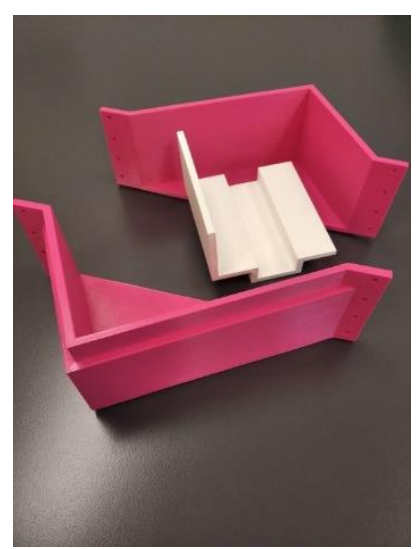

(b)

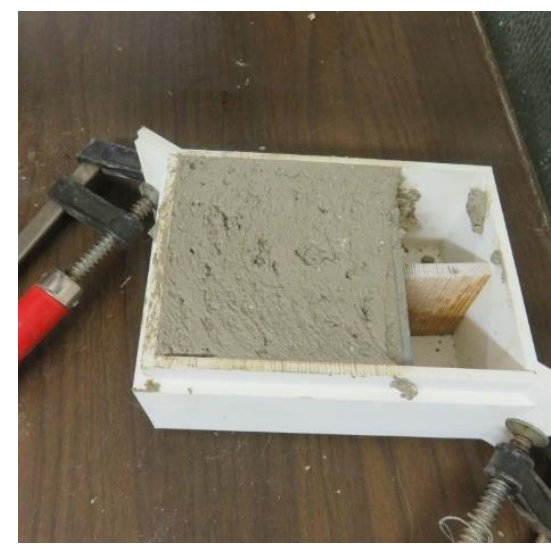

(d)

Figure 7. (a) Designed specimen (the dimensions are in $\mathrm{mm}$ ); (b,c) printed moulds; (d) curing phase.

On the other hand, calibrating the mechanical properties of the appropriate mortar was a crucial issue, and the first phase of the experimental program was aimed to obtain: 1) failure load values consistent with the designed setup (limit load $=500 \mathrm{~N}$ ) and within the valid range of the employed instrumentation; 2) failure modes corresponding to instantaneous and clear cutting of the lock from the main block (cohesive crack). After several attempts with traditional mortars, non-standard M1 and M2 mortars were finally defined, whose composition and curing time are reported in Table 1. The main components of M1 are Pozzolana, a volcanic material from Pozzuoli (Naples, Italy) with a range of colours between grey and red [36, 37], and lime, supplied by the Neapolitan company 
Cimmino Calce s.r.l., which is a calcium-containing inorganic mineral still extensively used as a building and engineering material. M2 is instead a cement-based mortar in which the cement took the place of lime, with different percentages. The mixtures were prepared using the amount of water required to ensure enough workability and normal consistency. According to the European Standard UNI EN 1015-2 [38], the pastes were compacted during the casting process to remove any air bubbles and voids. Curing was performed in ambient laboratory conditions (relative humidity $60 \pm 10 \%$ and $20 \pm 5^{\circ} \mathrm{C}$ ) until the test day (Figure $7 \mathrm{~d}$ ). Flexural and compressive tests were also carried out using standard equipment, based on the UNI EN 1015-11 [39], and the mean values of the measured density and strengths are summarized in Table 1.

Table 1: Composition and mechanical properties of the tested mortars.

\begin{tabular}{ccccccccc}
\hline Mortar & Pozzolana & Sand & Cement & Lime & $\begin{array}{c}\text { Curing } \\
\text { Time }\end{array}$ & $\begin{array}{c}\text { Flexural } \\
\text { strength } \\
{[\mathrm{MPa}]}\end{array}$ & $\begin{array}{c}\text { Compressive } \\
\text { strength } \\
{[\mathrm{MPa}]}\end{array}$ & $\begin{array}{c}\text { Density } \\
{[\mathrm{kN} / \mathrm{mc}]}\end{array}$ \\
\hline $\mathrm{M} 1$ & $50 \%$ & $24 \%$ & $2 \%$ & $24 \%$ & 28 days & 1.05 & 2.69 & 12.7 \\
\hline $\mathrm{M} 2$ & $47 \%$ & $38 \%$ & $15 \%$ & - & 28 days & 0.37 & 0.75 & 14.0 \\
\hline
\end{tabular}

\subsection{Test setup}

The test setup was specifically designed to investigate the pure shear and torsion-shear resistances of the lock interface, and to this aim several issues were taken into account. To minimise the effect of bending usually experienced during shear tests [32] and to neglect the pre-compression force, which are the main challenges of the classical experimental setup [31], a new setup was developed for the experimental tests.

Actually, a horizontal load was directly applied on the front face of the lock by the static gravity load via a pulley system, while the main body of the interlocking block was held fixed, until the collapse of the lock. On the other hand, to consider the pure shear resistance and torsion-shear combinations, different positions and orientations of the designed pulley system were explored.

The test setup is schematically shown in Figures 8a,b: the horizontal point-load was applied to the side face of the specimen lock by means of an electric hydraulic jack, monotonically increasing until the failure mechanisms. As shown in Figures 8b,c, the main body of the block was fixed to a wooden board to avoid sliding and to the upper support to avoid rotation, while the board was fixed to the upper support against sliding as well.

It is worth noting that this setup only allows torsion-shear combinations with low and intermediate eccentricities of the applied force (Figure 8c), while the simulation of the pure torsion moment would require the application of a couple of forces as carried out for dry-stacked units [16]. 


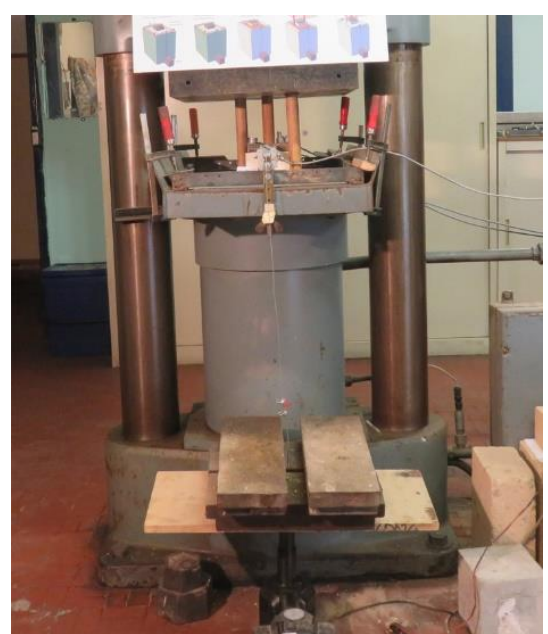

(a)

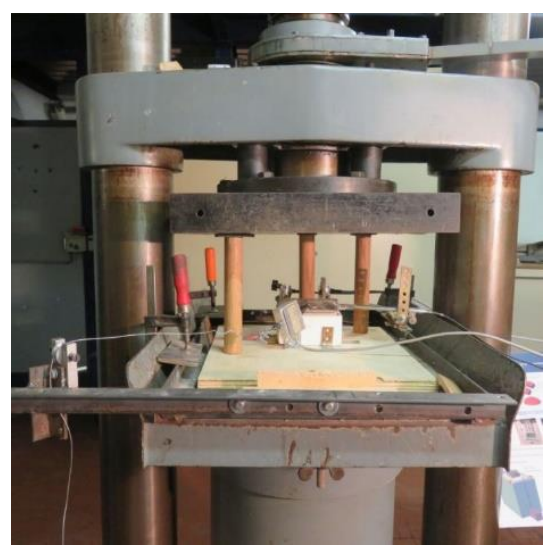

(c)

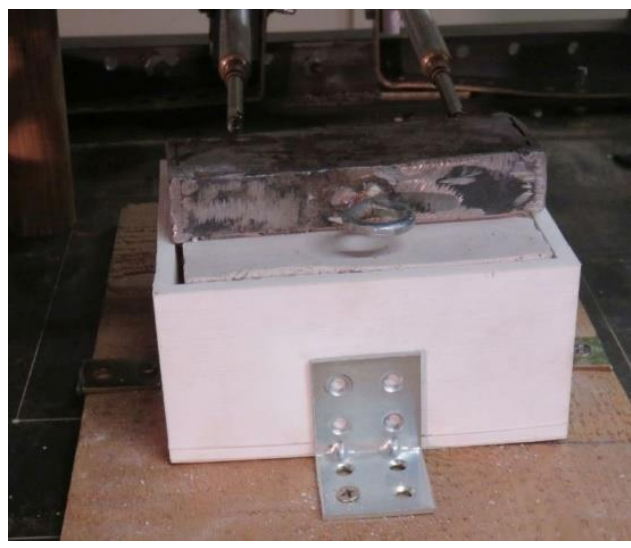

(e)

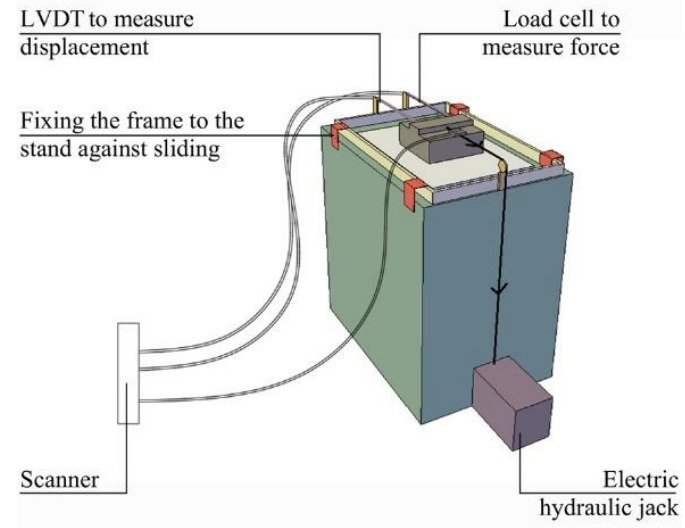

(b)

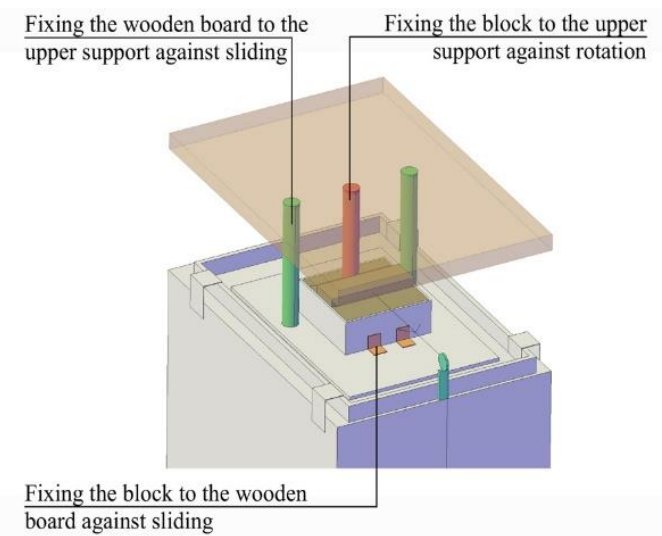

(d)

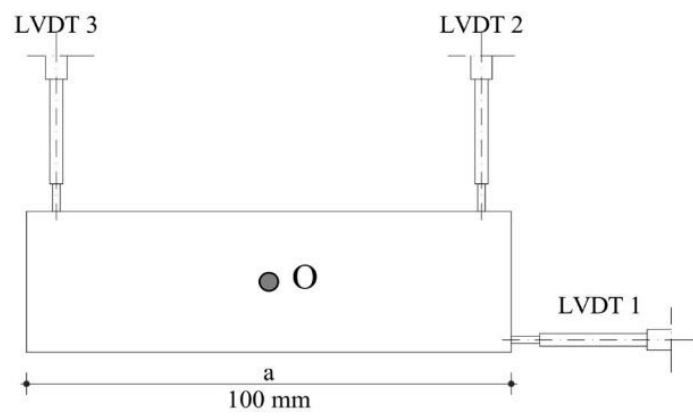

(f)

Figure 8. Test setup. (a,b) Displacement and load measurement; (c,d) constraints; (e) interlocking block with steel cup; (f) LVDT's position in the plan view.

The application of an iron cup on the lock allowed both to simulate this body as a rigid block and to distribute the applied shear force along the whole lock face (Figure 8e). On the other hand, the main body of the interlocking block was kept rigid during the tests by using a 3D printed rigid cup-shaped box. The load was applied under displacement control at a constant rate of $3 \mathrm{~mm} / \mathrm{min}$. 
Forces were measured using a load cell with $500 \mathrm{~N}$ maximum capacity and $10 \mathrm{~Hz}$ acquisition frequency, while the displacements were measured using Linear Variable Displacement Transducers (LVDTs) with a displacement range of $\pm 50 \mathrm{~mm}$. A digital scanner, distributed by Vishay Measurements Group, was employed to acquire transducers data.

To record both pure shear and torsion-shear failures, three LVDTs, supported by a steel frame, were positioned to the lateral and back sides of the lock, and numbered as shown in Figure 8f.

\subsection{Testing program}

The experimental program was planned to analyse the shear resistance of the lock interface in the case of pure shear (S1) and torsion-shear (S2, S3 and S4). The horizontal force, representing the shear force $V$, was applied at variable eccentricity and direction with respect to the vertical midplane of the lock.

As introduced above, the specimens made of two chosen mortars, M1 and M2, were tested using four setups, resulting in eight samples (Table 2):

- S1M1 and S1M2 for the limiting pure shear evaluation, each comprising four specimens;

- S2M1, S2M2, S3M1, S3M2, S4M1, S4M2 for the limiting torsion-shear evaluation, each comprising three specimens.

As shown in Table 2, the shear setup S1 was modified in S2-4 to allow the expected torsion-shear behaviour, in different ways:

- for $\mathrm{S} 2$, the force application point was moved on the lock, while $V$ was still orthogonal to the lock front side, with the eccentricity $e=25 \mathrm{~mm}$ from point $\mathrm{O}$;

- for S3, the force application point was only distanced from the centroid of the vertical lock face, with $V$ rotated $45^{\circ}$ counter clockwise, providing the eccentricity $e=29 \mathrm{~mm}$;

- for S4, the force application point was spaced from the lock and moved to a different position, with $V$ rotated $45^{\circ}$ clockwise, applying the eccentricity $e=51 \mathrm{~mm}$. 
Table 2: Experimental set configurations (the distances are in $\mathrm{mm}$ ).

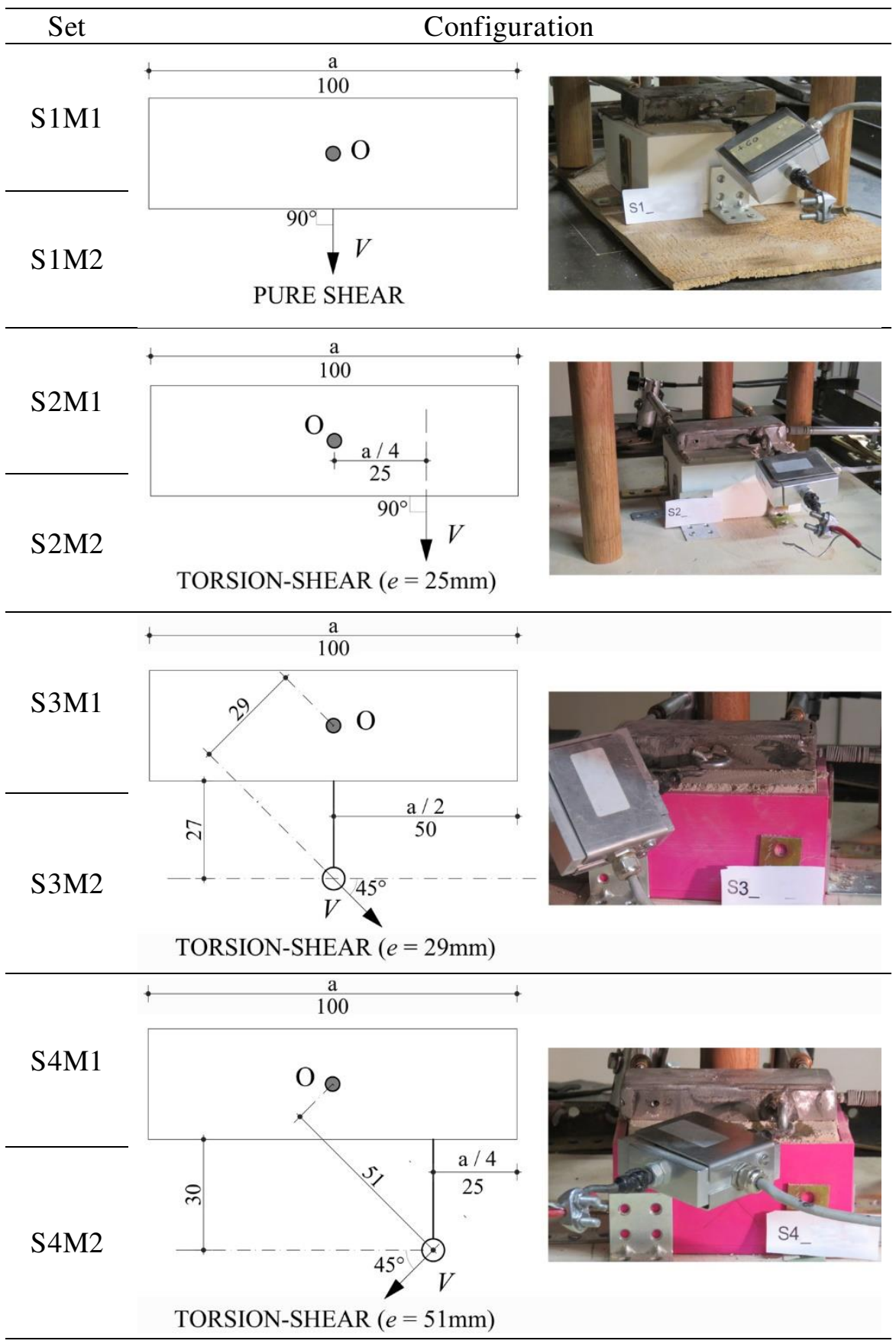

\subsection{Experimental results}

To determine the pure shear strength (cohesion) of the two mortars, 8 tests were carried out using the M1 and M2 mortar samples and the S1 shear test setup described in the previous sections. The limiting pure shear force for the two M1 and M2 mortars are collected in Table 3, together with the other sets. The coefficients of variation (CV) show a low dispersion of the frequency distributions and therefore a good reliability of the test setup. The averages of the limiting forces related to pure shear failure are $430 \mathrm{~N}$ and $240 \mathrm{~N}$ for the M1 and M2 mortars, respectively. The greater shear resistance of the M1 
mortar compared to M2 is in good agreement with similar trends for the compressive and flexural strength results shown in Table 1.

Table 3: Pure shear and torsion-shear resistances of the 26 specimens.

\begin{tabular}{|c|c|c|c|c|c|c|c|c|}
\hline \multirow{2}{*}{ Set } & \multirow{2}{*}{$\begin{array}{c}\text { ecc. } \\
{[\mathrm{mm}]}\end{array}$} & \multirow{2}{*}{ Mortar } & \multicolumn{3}{|c|}{ Shear force $V[\mathrm{~N}]$} & \multirow[b]{2}{*}{$\mathrm{T} 4$} & \multirow{2}{*}{$\mathrm{CV}[\%]$} & \multirow{2}{*}{$\begin{array}{c}\text { Average } V \\
{[\mathrm{~N}]}\end{array}$} \\
\hline & & & $\mathrm{T} 1$ & $\mathrm{~T} 2$ & T3 & & & \\
\hline \multirow{2}{*}{1} & \multirow{2}{*}{0} & M1 & 399 & 472 & 408 & 445 & 6.8 & 430 \\
\hline & & M2 & 250 & 242 & 226 & 243 & 3.7 & 240 \\
\hline \multirow{2}{*}{2} & \multirow{2}{*}{25} & M1 & 314 & 300 & 330 & - & 3.9 & 315 \\
\hline & & M2 & 213 & 203 & 181 & - & 6.7 & 199 \\
\hline \multirow{2}{*}{3} & \multirow{2}{*}{29} & M1 & 243 & 260 & 276 & - & 5.2 & 260 \\
\hline & & M2 & 181 & 193 & 192 & - & 2.9 & 189 \\
\hline \multirow{2}{*}{4} & \multirow{2}{*}{51} & M1 & 79 & 177 & 195 & - & 33.9 & 150 \\
\hline & & M2 & 118 & 133 & 106 & - & 9.3 & 119 \\
\hline
\end{tabular}

For this setup (pure shear), two LVDTs were used to verify the effective displacements of the lock in the absence of torsion. Figures $9 \mathrm{a}, \mathrm{b}$ show the load-displacement curves referred to some of the four tests performed on each of the M1 and M2 mortars, i.e. T2 Test in Figure 9a, and T1 and T3 Tests in Figure 9b. From these figures it is first evident the quasi-brittle behaviour of the material for both mortars. It is then worth emphasizing that the displacements of the two LVDTs, registered as channels Ch. 2 and Ch.3 in the figure, substantially tend to overlap for each test. This result confirms once again the reliability of the setup realized ad hoc, since the specimens collapsed in pure shear without torsion effect. The maximum capacity values shown in the graphs correspond to the limiting forces collected for the corresponding tests in Table 3 .

The S2-3-4 setups were developed to analyse the torsion-shear resistance of the lock. These setups differ from each other in the eccentricity of the applied force. To determine the torsion-shear strength of the two mortars, a total of 18 specimens, three per each set and mortar, were made out on the M1 and M2 mortar samples, as reported in Table 3. The first interesting remark is that the values of the forces $\mathrm{V}$ related to torsion-shear failure of each mortar decrease with increasing eccentricity, as expected. The small coefficients of variation $\mathrm{CV}$, except one, still show quite a good reliability of the setup adopted.

On the other hand, through the load-displacement curves in Figures 9c-f, it is possible to confirm the quasi-brittle behaviour of the involved materials and to analyse the rotation of the lock until collapse and its consistency with the eccentric load applied. Unlike the curves for pure shear in Figures 9a,b, where the displacements of LVDT Ch. 2 and Ch. 3 tend to coincide, for the torsion-shear condition the displacements are very different from each other. In particular, before the collapse of the lock, the displacements of the LVDT Ch.3 are generally limited into $0.5 \mathrm{~mm}$, while the displacements recorded by the LVDT Ch.2 are even six times higher than those of the LVDT Ch.3. Using three LVDTs allows 
to record three final displacements at the moment of the lock failure and therefore to build the final deformation. Further investigation will be carried out to define the pure torsion strength as well, so that analytical yield domains in torsion-shear interaction can be experimentally validated, similarly to what developed in [16] for dry-stacked tuff blocks.

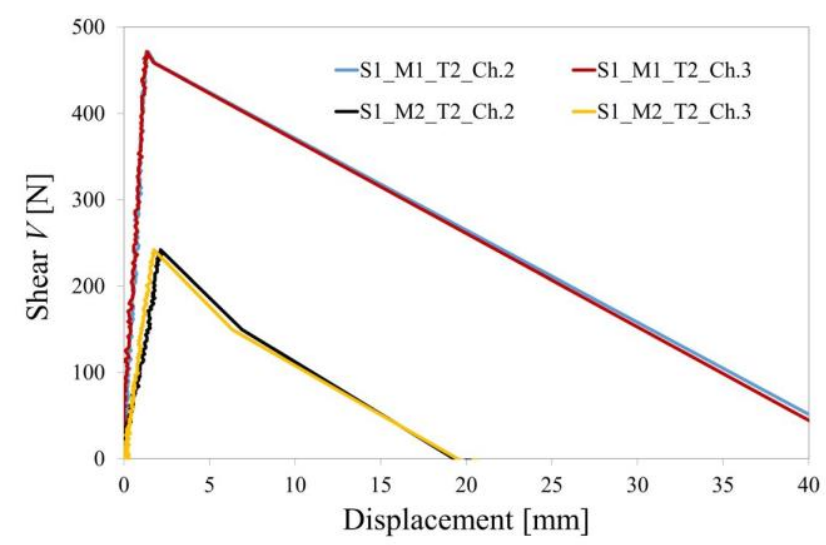

(a)

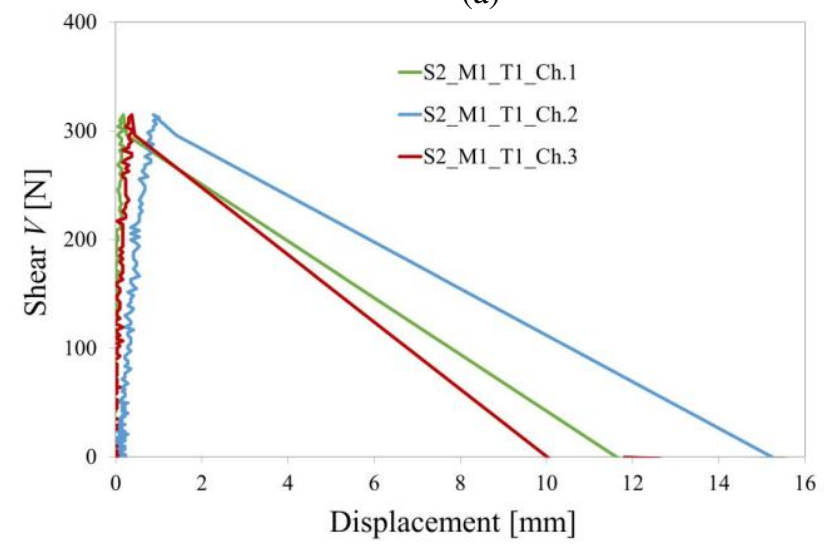

(c)

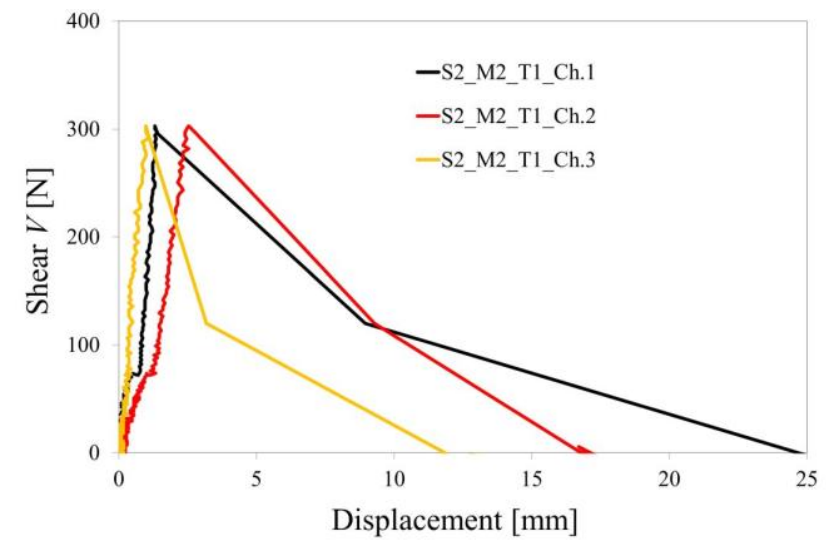

(e)

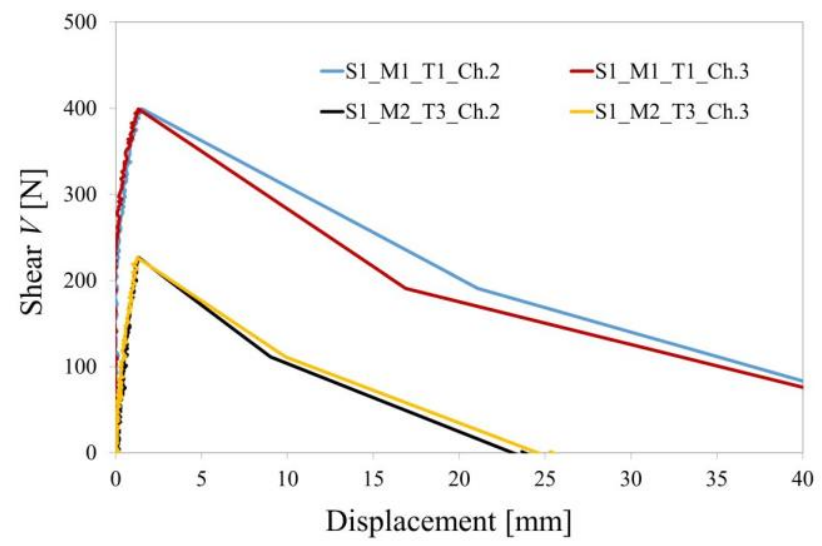

(b)

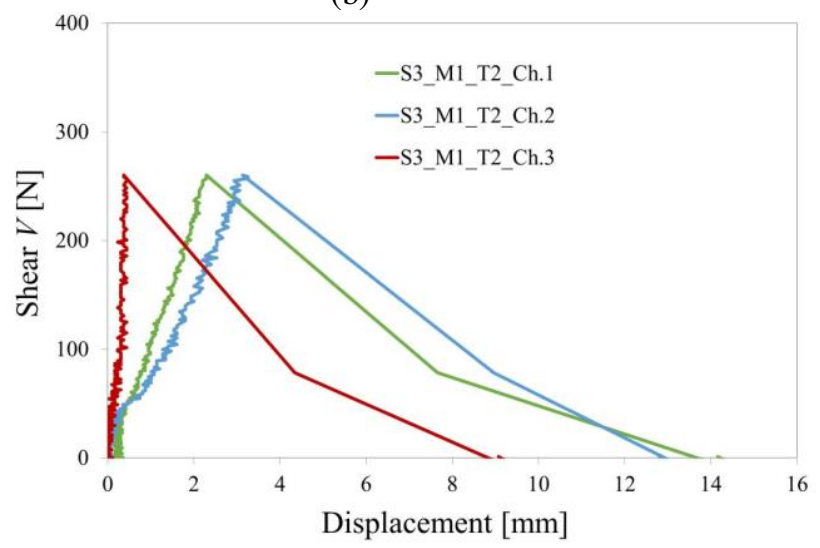

(d)

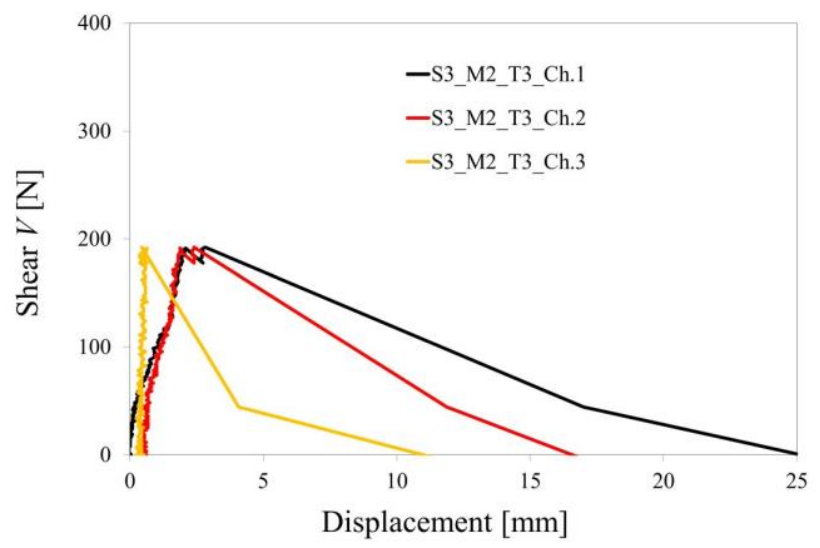

(f)

Figure 9. Load-displacement curves for S1 tests: (a) M1_T2 - M2_T2 and (b) M1_T1-M2_T3. Load-displacement curves for S2 and S3 tests and: (c,d) M1 and (e,f) M2 mortars.

\section{Comparison of analytical, numerical and experimental results}

This section presents the analytical and numerical results and their comparison with each other and against the experimental outcomes, with reference to the torsion-shear interactions on the lock 
interface of the simple interlocking block experimentally investigated (Figure 7a). The analytical results include those obtained by the convex, concave and corrected concave formulations described in Section 2, while the numerical results are referred to the three face triangulation types (normal, radial and rad8) used in 3DEC. For each mortar, the value of the pure shear force is considered as the mean value of the experimental results displayed in Table 3, that are 430N and 240N for M1 and M2 mortars, respectively. The cohesion values adopted for the $3 \mathrm{DEC}$ analyses are $\tau_{0}=0.14 \mathrm{~N} / \mathrm{mm}^{2}$ for M1 and $\tau_{0}=0.08 \mathrm{~N} / \mathrm{mm}^{2}$ for M2, which are obtained applying Eq. (1).

The first remark is that the curves related to the two different orientations of the applied shear force (orthogonal and $45^{\circ}$ inclined to the vertical lock face) provide close results for both the 3DEC and the convex models, as shown in Figure 10a,b referred to Mortar 1. In particular, the curves referred to $45^{\circ}$ inclined forces provide slightly higher values for all the cases and this allows to proceed with the more conservative results related to the orthogonal shear force. The similarity of these results is mainly due to the fact that both the distances of the instantaneous twisting centre and the corresponding applied shear force from the centroid of the interface almost lay on the same line, whatever the inclination of the force, as highlighted in [35]. It is also important to note that the outcomes of the 3DEC model in Figure 10a are represented by quite linear curves, with the same pure shear force but different pure torsion moments. This tendency is also followed by the analytical curves, though they are not linear but parabolic arcs.

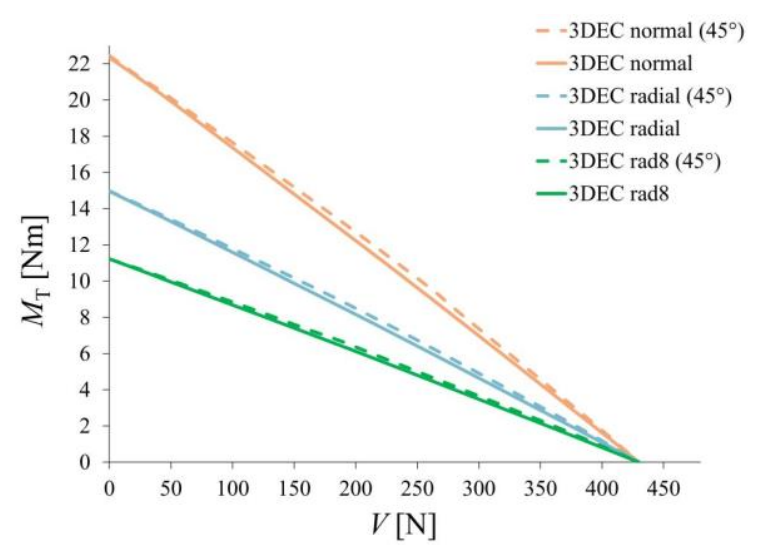

(a)

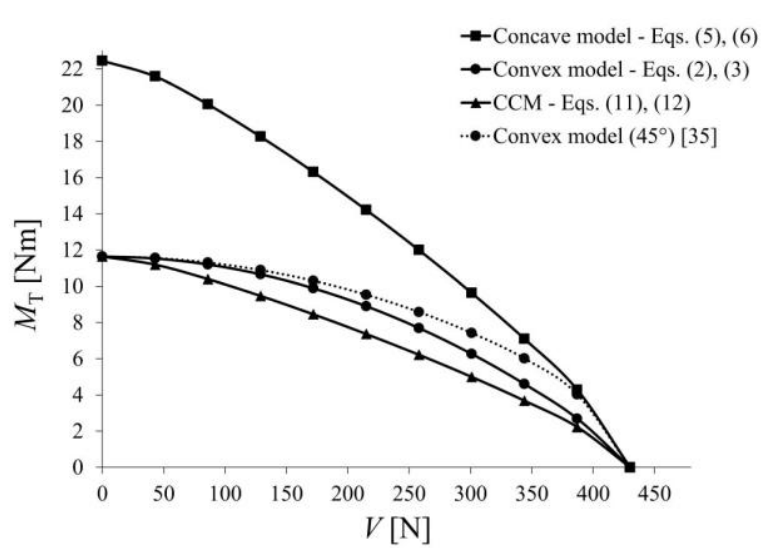

(b)

Figure 10. Numerical results for orthogonal and $45^{\circ}$ inclined shear forces and M1 mortar, obtained by the: (a) 3DEC model and (b) convex model.

In order to be compared, all the numerical and experimental results are collected in Figures 11a and $12 \mathrm{~b}$ with reference to the M1 and M2 mortars, respectively.

By comparing the numerical and analytical results, from both figures it emerges that the upper and lower lines of the 3DEC results seem to be the chords with the same endpoints as the parabolic curves provided by the concave and convex formulations, respectively. This suggests that the 3DEC normal 
model is more similar to the concave model, while the 3DEC rad8 model is close to the convex model and even closer to the corrected concave model (CCM in the figure).

The most interesting remark regards the comparison of the numerical results with the experimental ones, based on the assumption that the numerical value for the pure shear condition of both mortars is the mean value of the corresponding experimental results S1. Figure 11a shows that, for the M1 mortar specimens, the torsion-shear with low eccentricity (S2) provides results between the two upper curves obtained by 3DEC and the concave formulations, while the experimental results corresponding to the $45^{\circ}$ inclined forces (S3 and S4) with increasing eccentricities mostly straddle the curve obtained by the convex model. It is also evident that one of the S4 specimens is very far from the others and can be discharged. On the other hand, similar results can be observed for M2 from Figure 11b, though with lower results predicted by the same models as for M1 and some anomaly for S3. In fact, from this figure it can be observed that both the 3DEC normal and the concave models underestimate the experimental values for S2, while the 3DEC $\operatorname{rad} 8$ and the convex model underestimate the experimental values for $\mathrm{S} 4$, but the results for the $\mathrm{S} 3$ sample are even higher than the concave curve. Increasing the density of the interface subdivision by 3DEC will provide greater discrepancies with the analytical and experimental results, as shown for the 3DEC divide-join rad8 model in Figure 11a. Besides, it should also be considered that the experimental results on the cohesive joint are affected by the mechanism of dilatancy, which tends to increase with the decrease of shear displacement and compression [1, 41] and therefore to provide lager values of the initial shear strength (cohesion) [42]. Although this is a complex issue as addressed in [43], it suggests that the analytical and numerical curves herein obtained in favour of safety and without considering dilatancy would be sufficiently reliable even in the presence of compression on the joints, as actually occurs in real structures.

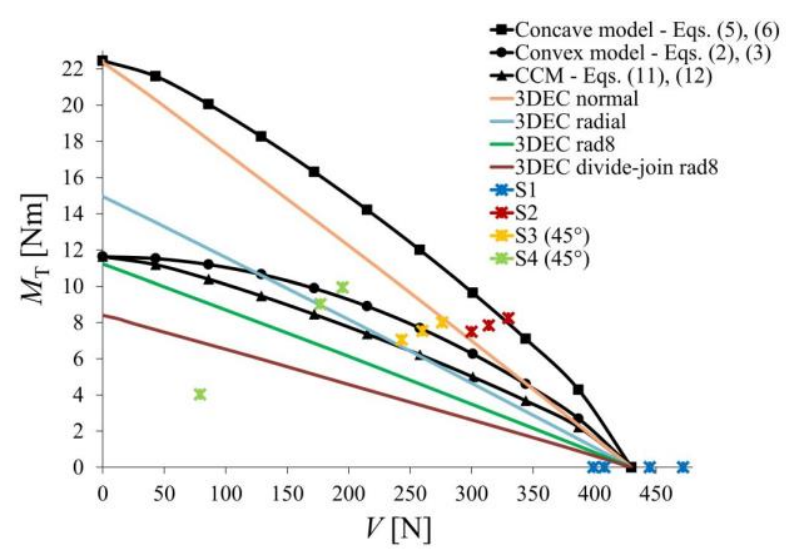

(a)

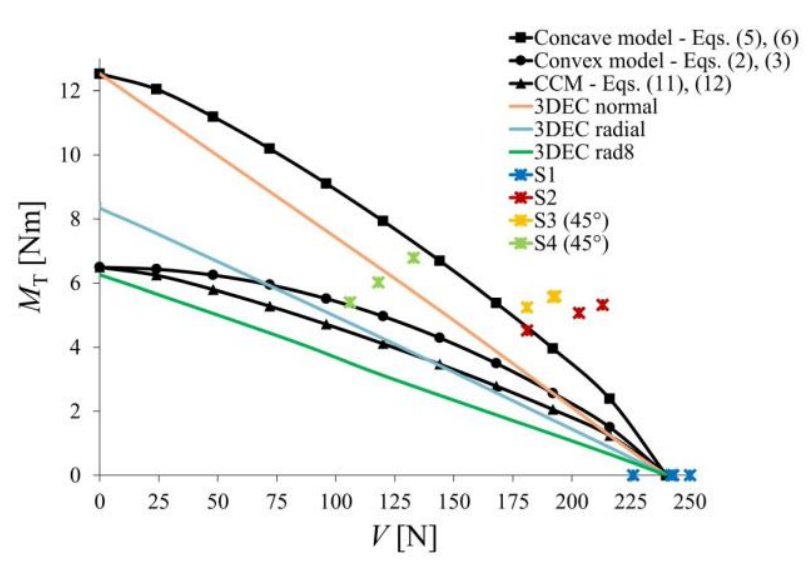

(b)

Figure 11. Numerical and experimental results for orthogonal shear forces and (a) M1 and (b) M2 mortars.

Another interesting remark is that the shear stress distributions at the contact for the different models and types of discretization are in good agreement with the compared results. As an example, Figure 
12 reports the stress distributions for the S4-M2 case (torsion-shear with large eccentricity), where the position of the torsion centres of the conservative models, i.e. the analytical convex (Figure 12b) and the 3DEC rad8 (Figure 12e) models, are very close to each other and they both well represent the experimental cracking of the lock (Figure 12a).

It can be concluded that, although further experimental results are needed, especially referred to larger eccentricities towards the pure torsion moment, the comparison of all the results show that the analytical concave and corrected concave models may respectively represent the upper and lower bounds of the torsion-shear behaviour of a cohesive joint. Moreover, the curves obtained by 3DEC normal and rad8 models are the conservative lines of these curves.

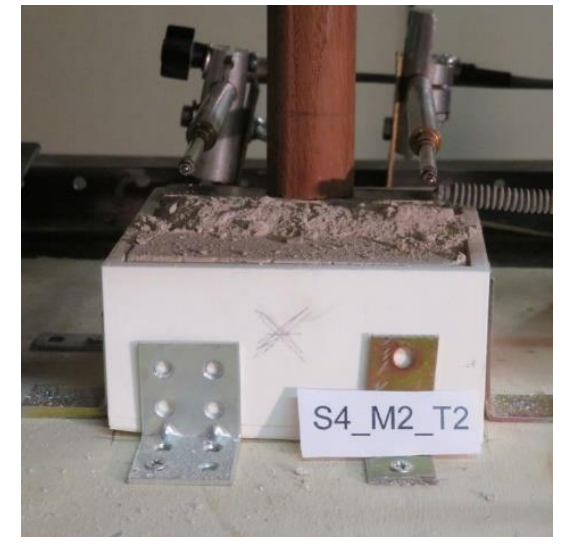

(a)

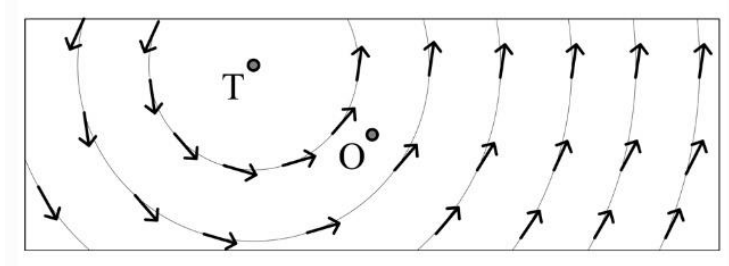

(b)

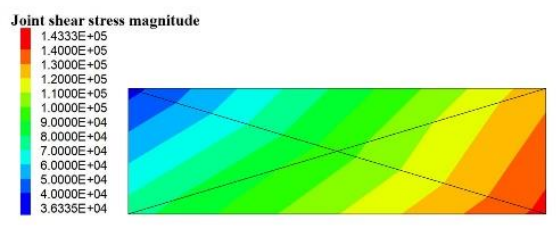

(c)

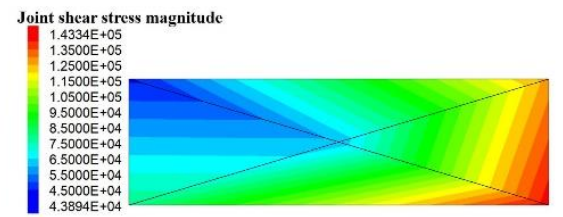

(d)

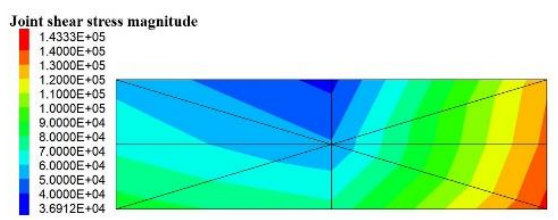

(e)

Figure 12. S4-M2 case. (a) Experimental cracking and shear stress distributions for the (b) convex model and the (c-e) 3DEC face triangulation types.

\section{Conclusions}

Analytical, numerical and experimental approaches have been presented in this paper to investigate the torsion-shear capacity of the contact interface between the lock and the main body of an interlocking block, assumed to have a cohesive behaviour.

Three analytical formulations, i.e. the concave, convex and "corrected" concave models, previously developed for assemblages of rigid blocks with conventional planar joints, have been extended to investigate the torsion-shear capacity of the lock connection, introducing a shear resistance independent of the normal force, based on the Tresca yield criterion and the cohesion as limit value. Like the conventional planar dry interface, the overestimation of the pure torsion capacity in the 
concavity model with respect to the convex formulation has also been observed in the lock connection of the interlocking block, confirming the higher reliability of the "corrected" concave model.

Numerical analyses employing the modelling code 3DEC for advanced analysis of discontinuous media have been carried out on an interlocking cuboidal block with a cuboidal lock on its main body, to model the interlocking interface. As point loads cannot be applied to the rigid block boundary in 3DEC, lateral forces applied to the upper lock have been simulated as non-uniformly distributed forces with a linear gradient, and with different shear stress distributions varying with the face triangulation type. In particular, "radial" and "rad8" triangulations provided by 3DEC have been used, obtaining different ultimate forces, with differences increasing with eccentricity.

The third approach herein presented is the experimental investigation carried out on the simplest interlocking block, composed of a main body with a prismatic lock located on its upper face and subjected to lateral loading in absence of normal force. An ad hoc test setup was realized to estimate the initial shear and torsion-shear strengths at the lock interface, with results reported in terms of loaddisplacement curves. Two cement-based mortars M1 and M2 were used for specimens, casted using moulds provided by a 3D printer.

Comparing analytical and numerical results on the interlocking block experimentally tested, the following comments are interesting to underline:

- in both cases, the two different orientations of the applied shear force (orthogonal and $45^{\circ}$ inclined to the vertical lock face) provide close results, with more conservative values obtained for the orthogonal direction;

- assuming the same pure shear values, different pure torsion values are attained by the four numerical models for the interlocking interface (normal, radial, rad8, and divide-join rad8) and analogous observations can be made for the three analytical models (concave, convex and "corrected" concave); - the 3DEC normal model is similar to the concave model, while the 3DEC rad8 model is close to the convex model and even closer to the "corrected" concave model;

Comparing the analytical and numerical results with experimental ones allows the following comments:

- both for M1 and M2, experimental results corresponding to the $45^{\circ}$ inclined forces with increasing eccentricities mostly straddle the curve obtained by the convex model, while the torsion-shear condition with low eccentricity and orthogonal shear forces provides results between the two upper curves obtained by 3DEC and the concave formulations, even if with upper values for M2;

- increasing the density of the interface subdivision by 3DEC, e.g. with divide-join rad8, is not convenient since providing greater discrepancies with both analytical and experimental results. 
In conclusion, the analytical concave and "corrected" concave models, and the corresponding parabolic curves obtained, can be assumed as the upper and lower bounds of the torsion-shear behaviour of a cohesive joint, while the 3DEC normal and rad8 models, and the corresponding linear curves obtained, can be considered their conservative interpretation.

Acknowledgements The authors wish to express their gratitude to Mr. Domenico Imperatrice from the Laboratory of DiSt in Napoli, for his helpful assistance and support in the execution of the experimental investigations.

Funding $\quad 3$ This project has received funding from the European Union's Horizon 2020 research and innovation programme, under the Marie Skłodowska-Curie Grant Agreement No. 791235. Open access funding provided by Università degli Studi di Napoli Federico II within the CRUI-CARE Agreement.

\section{Compliance with ethical standards}

Conflict of Interest The authors declare that they have no conflict of interest.

\section{REFERENCES}

[1] Lourenço, P.B. (2009). Recent advances in masonry structures: Micromodelling and homogenisation. In: Galvanetto U, Aliabadi MHF (Eds.), Multiscale Modeling in Solid Mechanics. Imperial College Press; p. 251-294.

[2] Cundall, P.A. (1980). UDEC-A generalized distinct element program for modelling jointed rock. Final Technical Report, European Research Office (US Army Contract DAJA37-79-C0548); NTIS order No. AD-A087 610/2.

[3] Hart, R., Cundall, P.A. and Lemos, J. (1988). Formulation of a three-dimensional distinct element model-Part II. Mechanical calculations for motion and interaction of a system composed of many polyhedral blocks. International Journal of Rock Mechanics and Mining Sciences and Geomechanics, 25(3): 117-125.

[4] ITASCA (2020), 3DEC online manual, version 5.2.

[5] Lemos, J.V. (2007). Discrete element modeling of masonry structures. International Journal of Architectural Heritage, 1(2): 190-213.

[6] Simon, J. and Bagi, K. (2016). Discrete element analysis of the minimum thickness of oval masonry domes. International Journal of Architectural Heritage, 10(4): 457-475.

[7] Rigó, B. and Bagi, K. (2018). Discrete element analysis of stone cantilever stairs. Meccanica, 53(7): 1571-1589.

[8] Sarhosis, V., Lemos, J.V. and Bagi, K. (2019). Discrete element modeling. In: Numerical modeling of masonry and historical structures, Chapter 13, Woodhead Publishing, pp. 469-501.

[9] McInerney, J. and DeJong, M. (2015). Discrete element modeling of groin vault displacement capacity. International Journal of Architectural Heritage, 9(8): 1037-1049.

[10] Pulatsu, B., Erdogmus, E., Lourenço, P.B., Lemos J.V. and Tuncay, K. (2020). Simulation of the in-plane structural behavior of unreinforced masonry walls and buildings using DEM. Structures, 27: 2274-2287. 
[11] Foti, D., Vacca, V. and Facchini, I. (2018). DEM modeling and experimental analysis of the static behavior of a dry-joints masonry cross vaults. Construction and Building Materials, 170: 111-120.

[12] Pulatsu, B., Gencer, F. and Erdogmus, E. (2020). Study of the effect of construction techniques on the seismic capacity of ancient dry-joint masonry towers through DEM. European Journal of Environmental and Civil Engineering, DOI: 10.1080/19648189.2020.1824823.

[13] Livesley, R.K. (1992). A computational model for the limit analysis of three-dimensional masonry structures. Meccanica, 27(3): 161-172.

[14] Casapulla, C. and Maione A. (2018). Modelling the dry-contact interface of rigid blocks under torsion and combined loading: concavity vs. convexity formulation. International Journal of Non-Linear Mechanics, 99: 86-96.

[15] Pantò, B., Casapulla, C. and Caliò, I. (2020). A discrete rotating links model for the non-linear torsion-shear-flexure behaviour of cohesive-frictional interfaces. Engineering and Computational Mechanics, under review.

[16] Casapulla, C. and Portioli, F. (2016). Experimental tests on the limit states of dry-jointed tuff blocks. Materials and Structures, 49(3): 751-767.

[17] Intrigila, C., Nodargi, N.A. and Bisegna P. (2019). Frictional behaviour of masonry interfaces: experimental investigation on two dry-jointed blocks. In: Conference of the Italian Association of Theoretical and Applied Mechanics. Springer, pp. 2032-2047.

[18] Giresini, L., Solarino, F., Paganelli, O., Oliveira, D.V. and Froli, M. (2019). One-sided rocking analysis of corner mechanisms in masonry structures: influence of geometry, energy dissipation, boundary conditions. Soil Dynamics and Earthquake Engineering, 123: 357-370.

[19] Giresini, L. (2017). Design strategy for the rocking stability of horizontally restrained masonry walls. In: 6th Thematic Conference on Computational Methods in Structural Dynamics and Earthquake Engineering, M. Papadrakakis, M. Fragiadakis (eds.).

[20] Liu, H., Liu, P., Lin, K. and Zhao, S. (2016). Cyclic behavior of mortarless brick joints with different interlocking shapes. Materials, 9(3): art. no. 166.

[21] Dyskin, A.V., Estrin, Y. and Pasternak, E. (2019). Topological Interlocking Materials, In: Y. Estrin et al. (Eds.): Architectured Materials in Nature and Engineering, Berlin, Springer, pp. 23-49.

[22] Ali, M., Gultom, R.J. and Chouw, N. (2012). Capacity of innovative interlocking blocks under monotonic loading. Construction and Building Materials, 37: 812-821.

[23] Ceraldi, C., D'Ambra, C., Lippiello, M. and Prota, A. (2017). Restoring of timber structures: connections with timber pegs. European Journal of Wood and Wood Products, 75(6): 957-971.

[24] Ceraldi, C., Lippiello, M., D'ambra, C. and Prota, A. (2018). The influence of dowel-bearing strength in designing timber pegged timber joints. International Journal of Architectural Heritage, 12(3): 362-375.

[25] Fang, D. and Mueller, C.T. (2018). Joinery connections in timber frames: analytical and experimental explorations of structural behavior. In: Proceedings of the Annual IASS Symposium 2018, pp. 1-8.

[26] Sassu, M., De Falco, A., Giresini, L. and Puppio, M. (2016). Structural solutions for low-cost bamboo frames: Experimental tests and constructive assessments. Materials, 9(5): art. no. 346.

[27] Casapulla, C., Mousavian, E. and Zarghani, M. (2019). A digital tool to design structurally feasible semi-circular masonry arches composed of interlocking blocks. Computers \& Structures, 221: 111-126. 
[28] Mousavian, E. and Casapulla, C. (2020). The role of different sliding resistances in limit analysis of hemispherical masonry domes. Frattura ed Integrità Strutturale, 51: 336-355.

[29] Mousavian, E. and Casapulla, C. (2020). Structurally informed design of interlocking block assemblages using limit analysis. Journal of Computational Design and Engineering, 7(4): 448468.

[30] Giresini, L., Puppio, M.L. and Taddei, F. (2020). Experimental pull-out tests and design indications for strength anchors installed in masonry walls. Materials and Structures, 53, art. no. 103.

[31] UNI EN 1052-3 (2007). Methods of test for masonry - Part 3: Determination of initial shear strength.

[32] Montazerolghaem, M. and Jäger, W. (2014). A comparative numerical evaluation of masonry initial shear test methods and modifications proposed for EN 1052-3. In: 9th International Masonry Conference (9IMC), Guimarães, Portugal, pp. 1-10.

[33] Tran-Cao, T. (2009). Collapse analysis of block structures in frictional contact. PhD thesis, Sydney (Australia): The University of New South Wales.

[34] Dowling, N.E. (1998). Mechanical behavior of materials. 2nd ed. New Jersey: Englewood Cliffs, Prentice-Hall.

[35] Casapulla, C. (1999). Resistenze attritive in una parete muraria soggetta ad azioni normali al suo piano medio. In: Proceedings of the National Conference "L'ingegneria Sismica in Italia" ANIDIS99, p- 1-12, Torino, Italy. (in Italian)

[36] Lippiello, M. (2011). Pozzolanic cementum of the ancient constructions in Campi Flegrei area. International Journal of Architectural Heritage, 5(1): 84-100.

[37] Lippiello, M., Ceraldi, C., D’Ambra, C. and Lignola, G.P. (2016). Mechanical characterization of ancient pozzolanic mortars with additions of brick and tuff dust: a comparative investigation.

In: K. Van Balen and E. Verstrynge (Eds.): Structural Analysis of Historical Constructions, Taylor \& Francis Group, pp. 558-564.

[38] UNI EN 1015-2 (2007). Methods of Test for Mortar for Masonry - Part 2: Bulk sampling of mortars and preparation of test mortars.

[39] UNI EN 1015-11 (2007). Methods of Test for Mortar for Masonry - Part 11: Determination of flexural and compressive strength of hardened mortar.

[40] Ali, N., Ashraf, M., Alam, H. and Ahmed Khan, F. (2016). Effect of precompression and mortar ratios on the in-plane shear strength of unreinforced brick masonry. International Journal of Advanced Structures and Geotechnical Engineering, 5(3): 78-82.

[41] van der Pluijm, R. (1999). Out-of-plane bending of masonry: behavior and strength. Ph.D. thesis, Eindhoven University of Technology, The Netherlands.

[42] van Zijl, G.P.A.G. (1999). Numerical formulation for masonry creep, shrinkage and cracking. Technical report, Engineering Mechanisms, vol. 1, series 11, Delft University Press, The Netherlands.

[43] Andreotti, G., Graziotti, F. and Magenes, G. (2019). Expansion of mortar joints in direct shear tests of masonry samples: implications on shear strength and experimental characterization of dilatancy. Materials and Structures, 52, art. no. 64. 
Figures

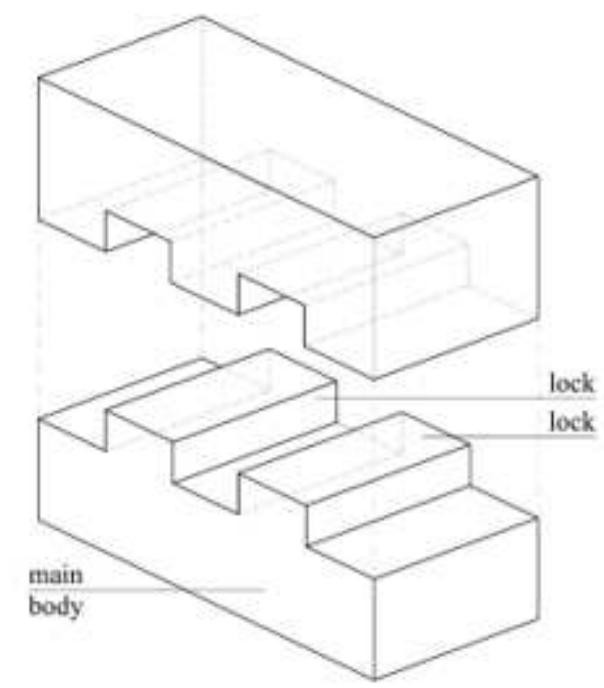

(a)

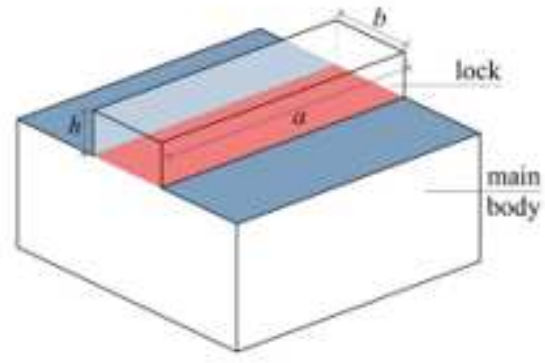

(b)

Figure 1

3D representation of an interlocking block with (a) three locks and (b) only one lock.

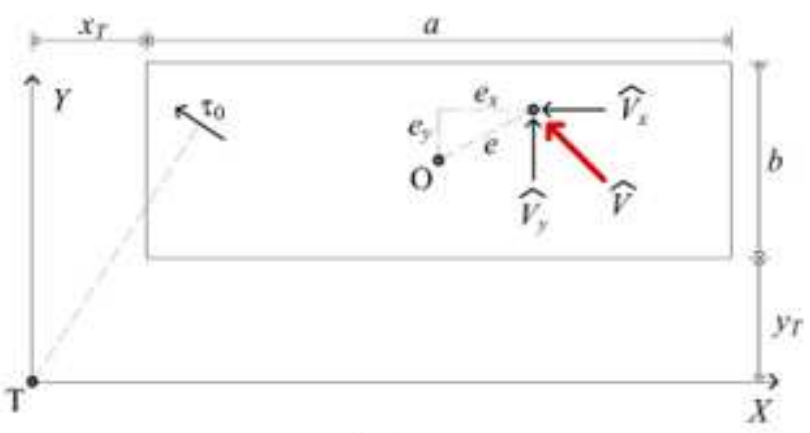

(a)

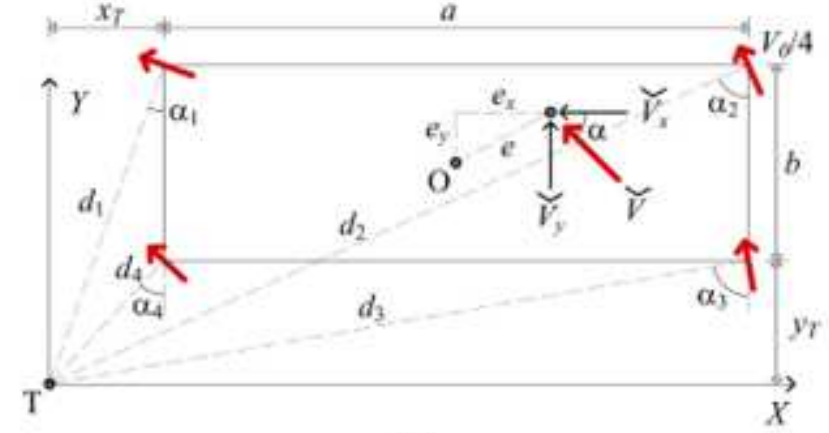

(b)

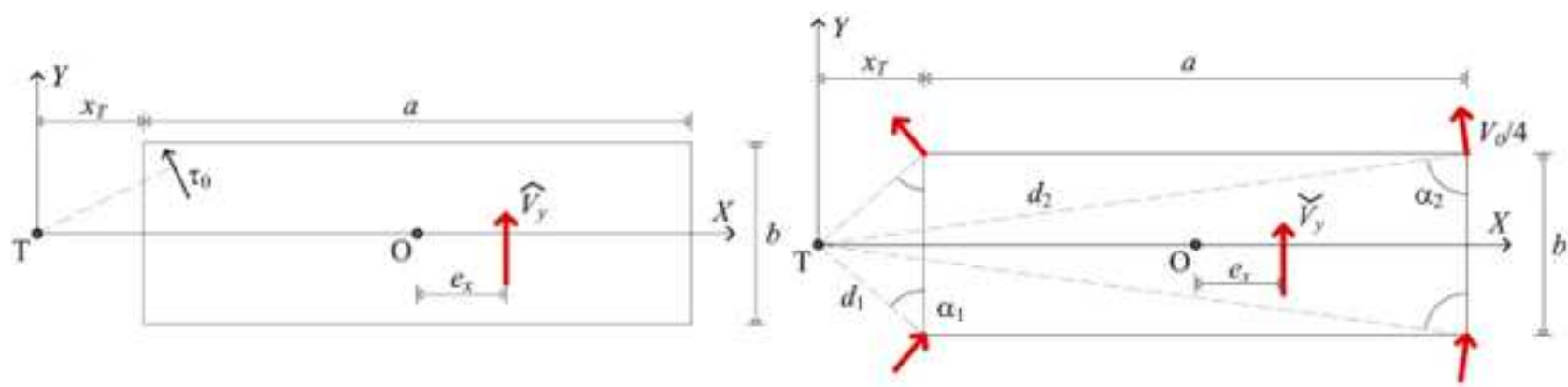

(c)

(d)

Figure 2

Torsion-shear interaction by the $(a, c)$ convex and $(b, d)$ concave contact interfaces. 


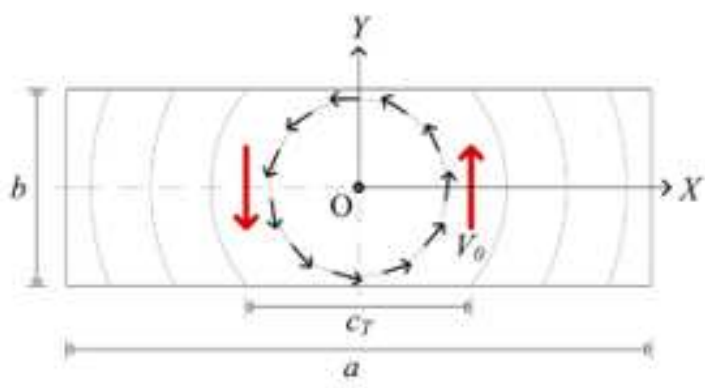

(a)

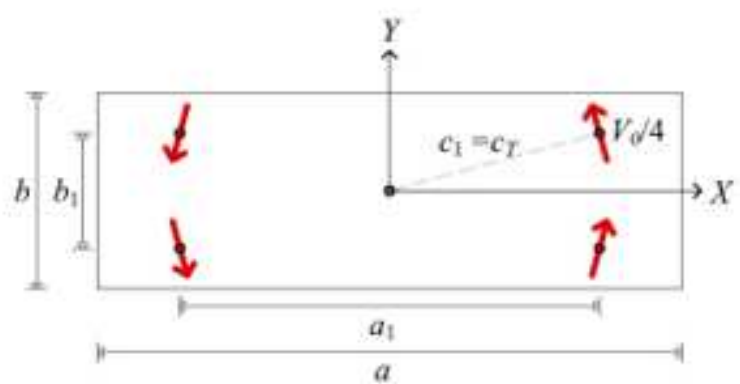

(b)

\section{Figure 3}

Shear stresses and/or forces over the (a) convex and (b) corrected concave contact interface under axial compression and pure torsion moment.

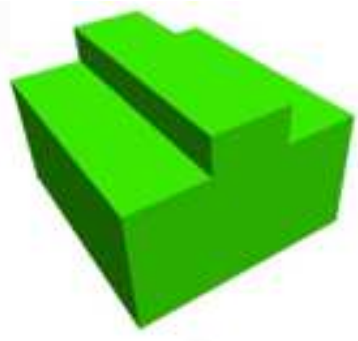

(a)

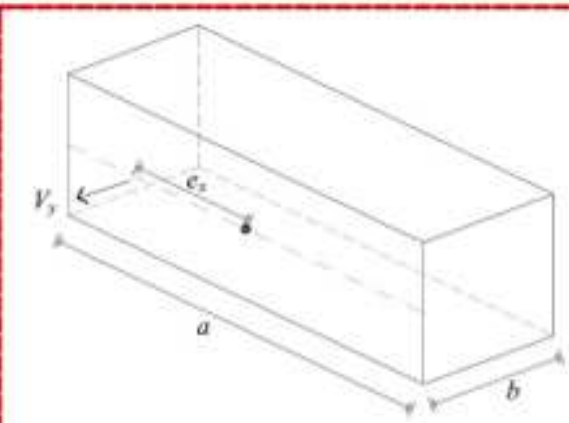

(c)

slope $k$

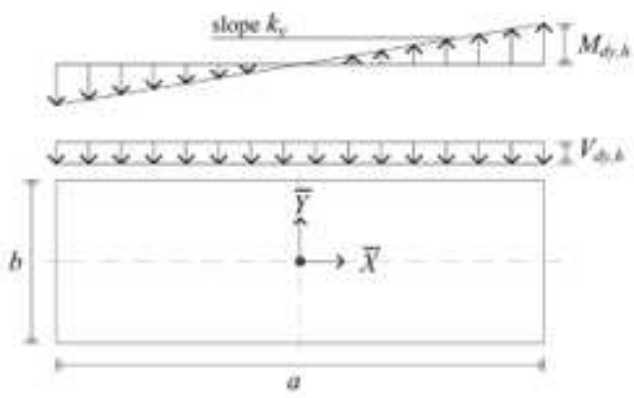

(c)

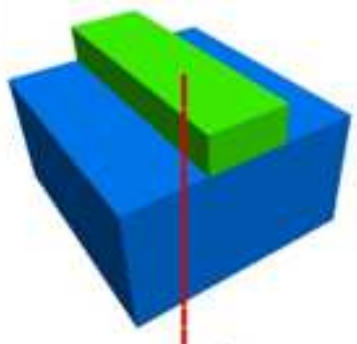

(b)

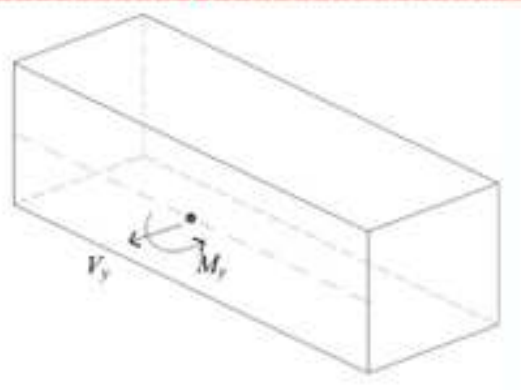

(d)

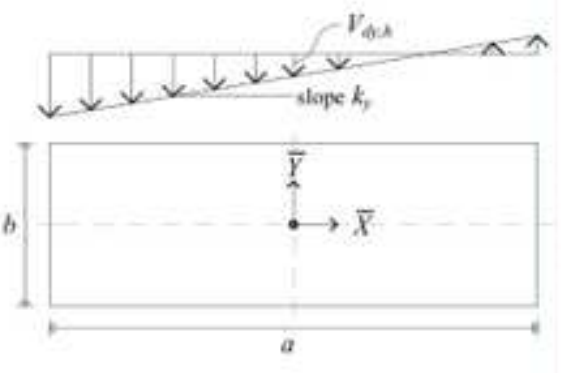

(f)

\section{Figure 4}

(a) Concaved shaped block modelled in 3DEC, (b) 3DEC Interlocking block modelled in this paper composed main body and lock with a cohesive contact, (c) to (f) replacing the pointed force normal to $\mathrm{X}$ 
axis with a linearly distributed force.

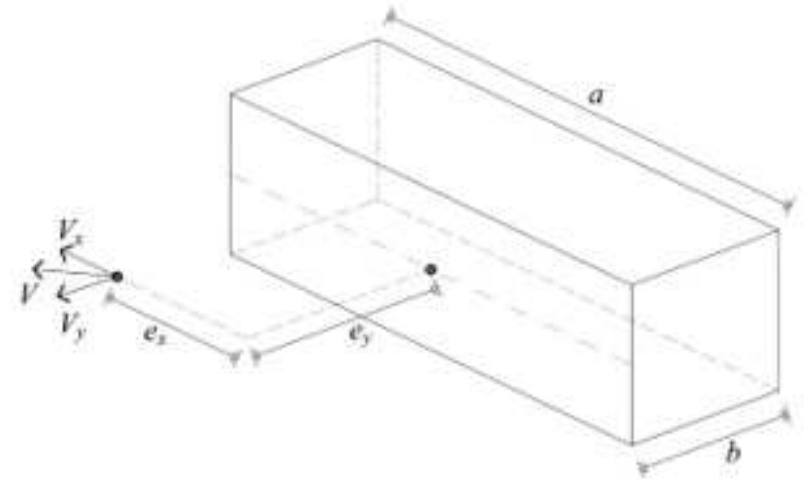

(a)

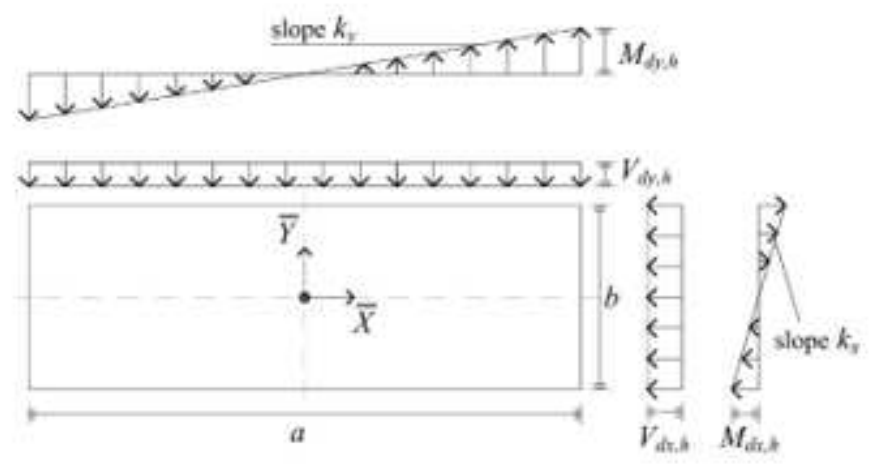

(c)

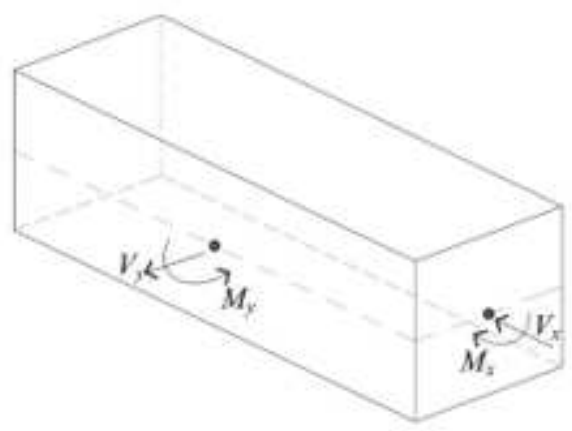

(b)

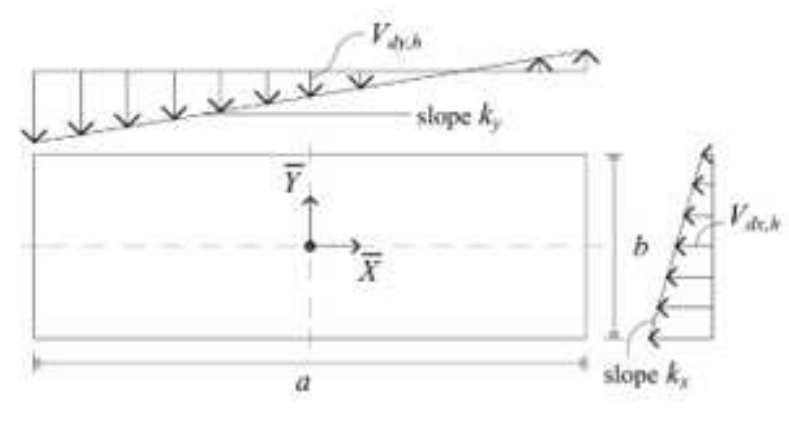

(d)

\section{Figure 5}

Replacing the pointed force $45^{\circ}$ inclined with respect to $X$ axis with two linearly distributed forces.

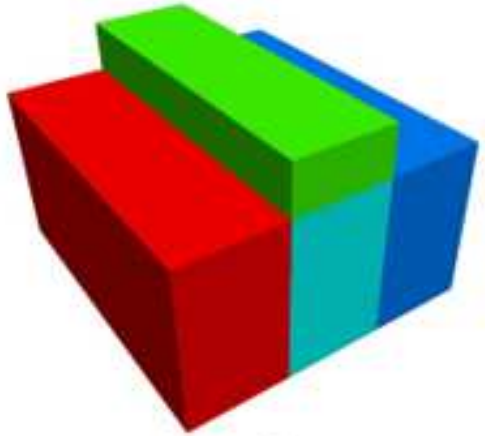

(a)

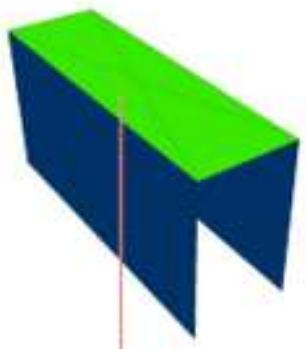

(b)

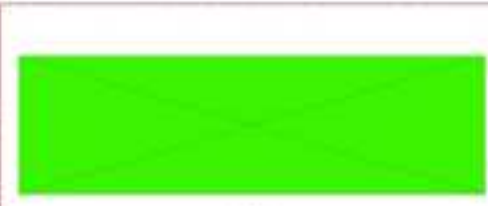

(c)

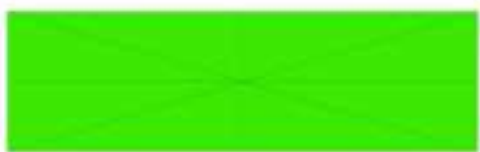

(d)

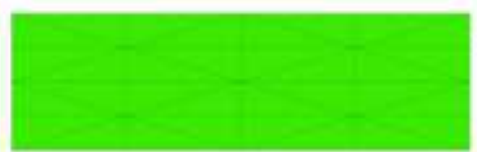

(c)

Figure 6 
$(a, b)$ Discretisation of the main body to remove the equilibration error; different face triangulation models for the contacts between rigid blocks as: (c) radial, (d) rad8 and (e) divide-join rad8.

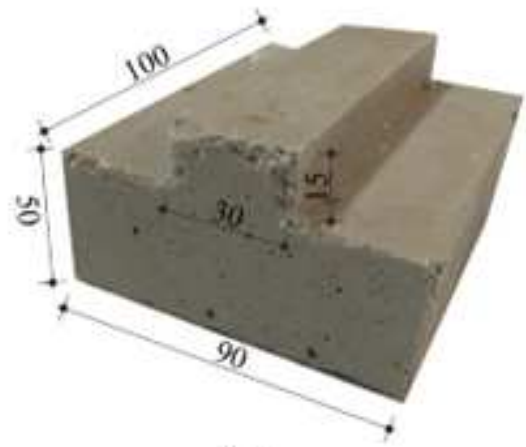

(a)

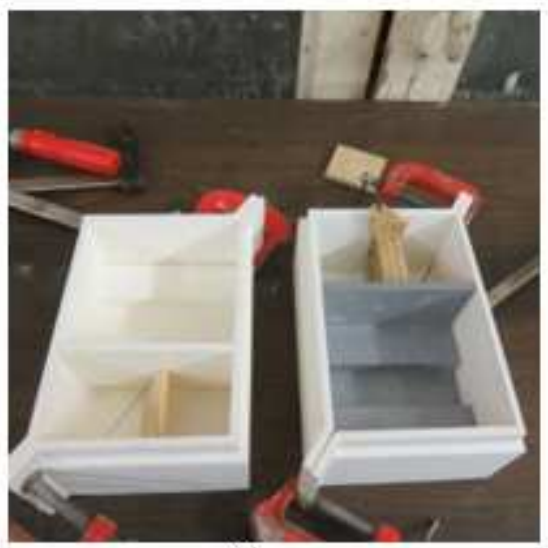

(c)

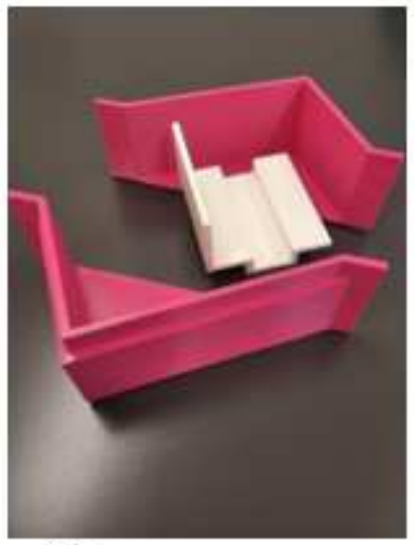

(b)

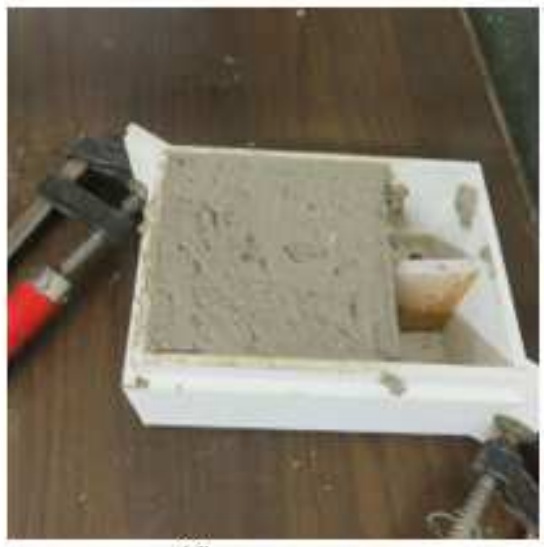

(d)

Figure 7

(a) Designed specimen (the dimensions are in $\mathrm{mm})$; (b,c) printed moulds; (d) curing phase. 


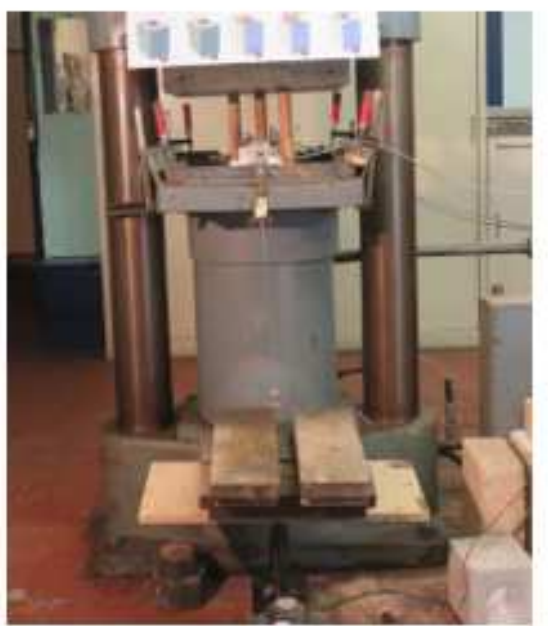

(a)

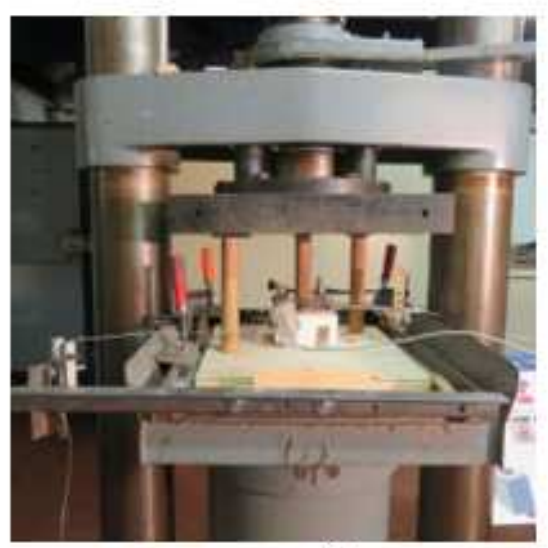

(c)

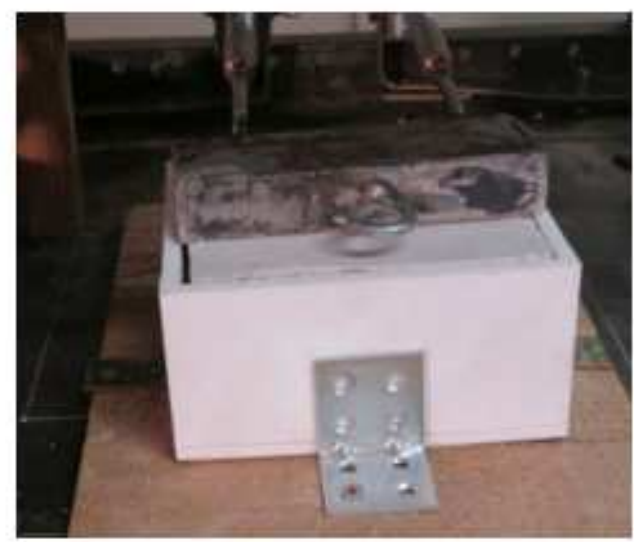

(e)

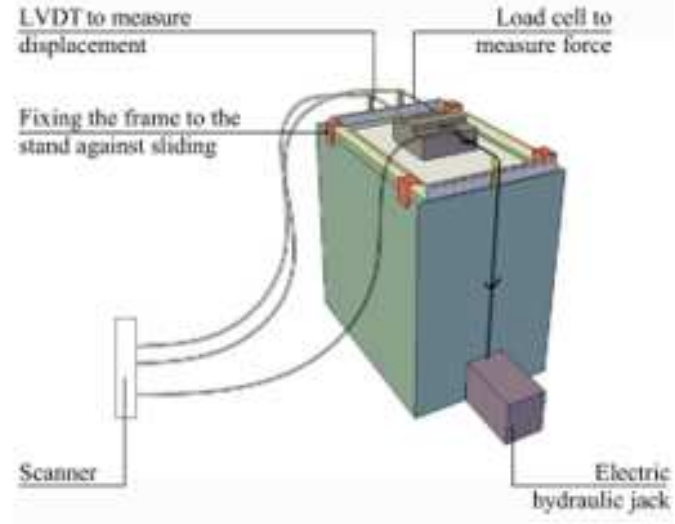

(b)

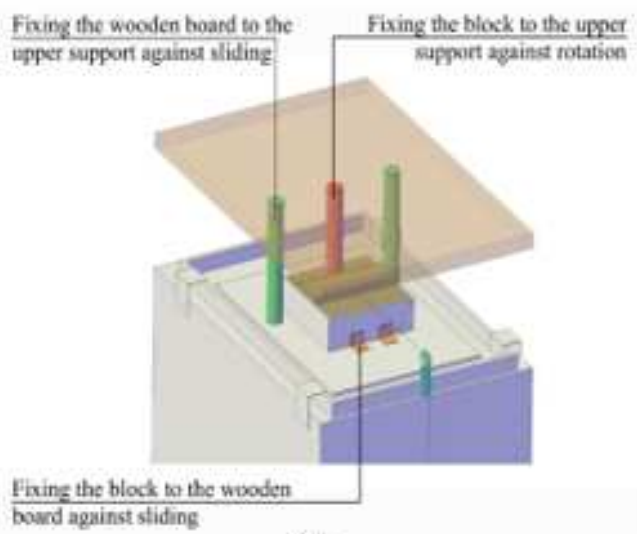

(d)

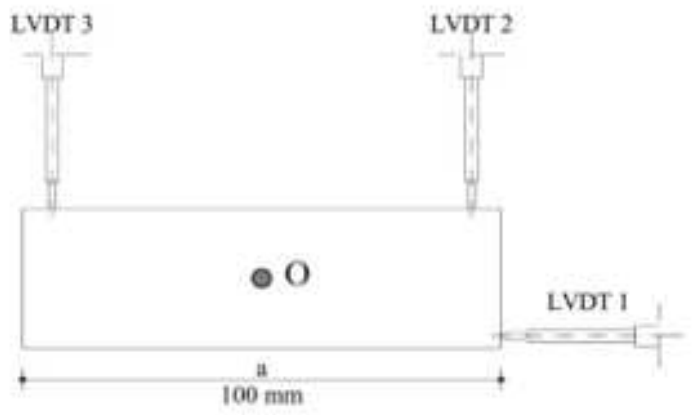

(f)

\section{Figure 8}

Test setup. (a,b) Displacement and load measurement; (c,d) constraints; (e) interlocking block with steel cup; (f) LVDT's position in the plan view. 


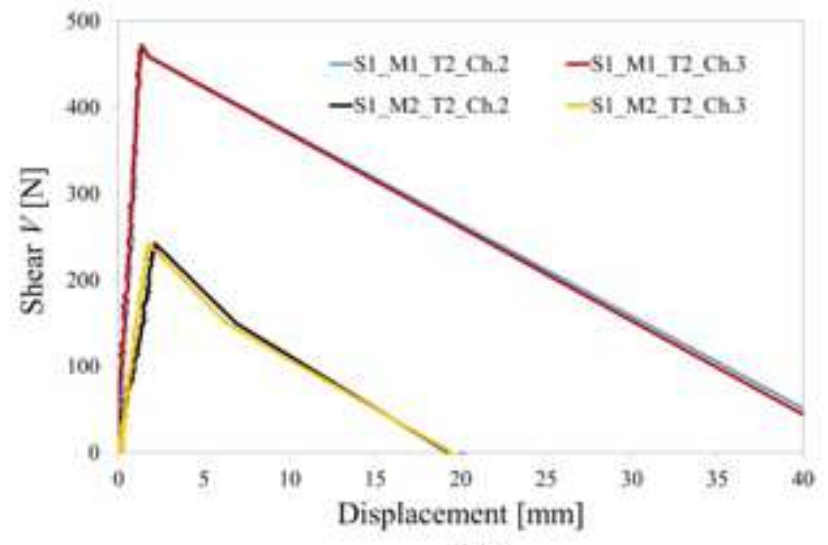

(a)

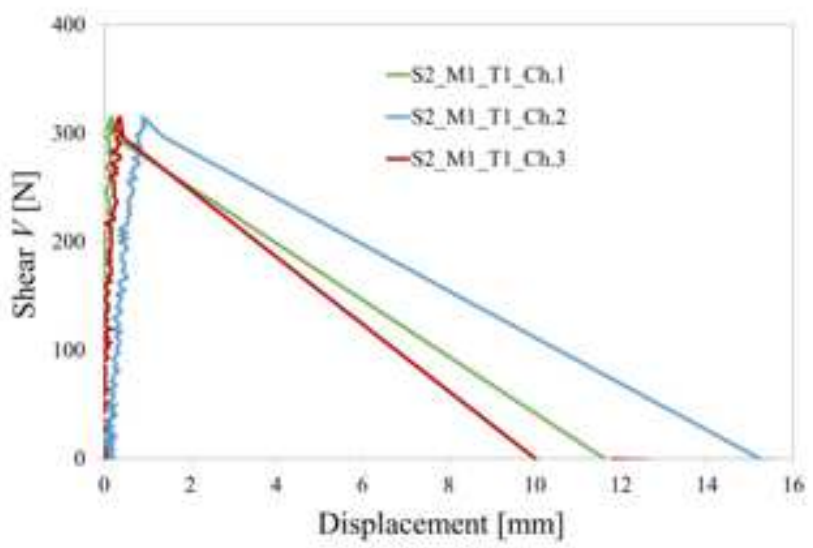

(c)

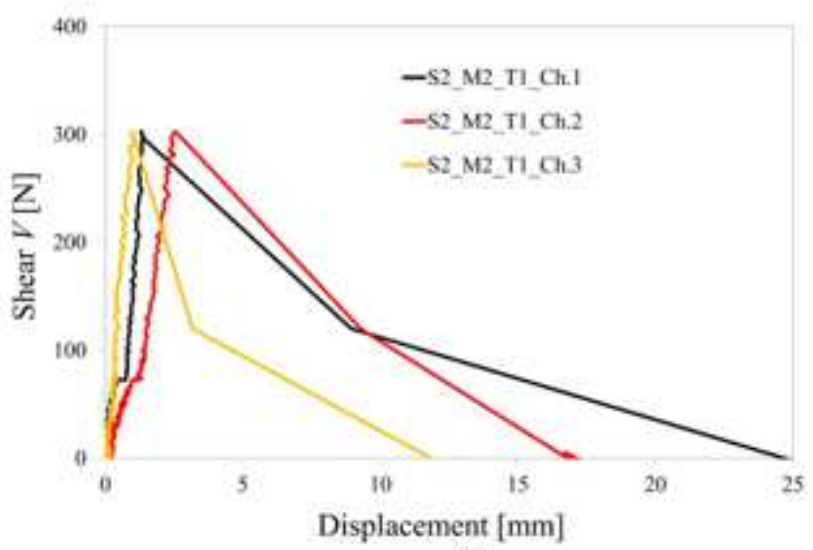

(e)

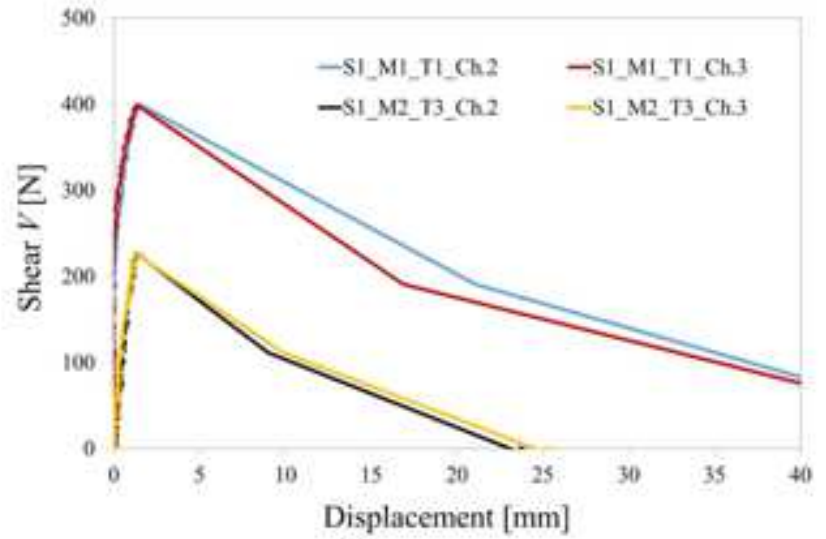

(b)

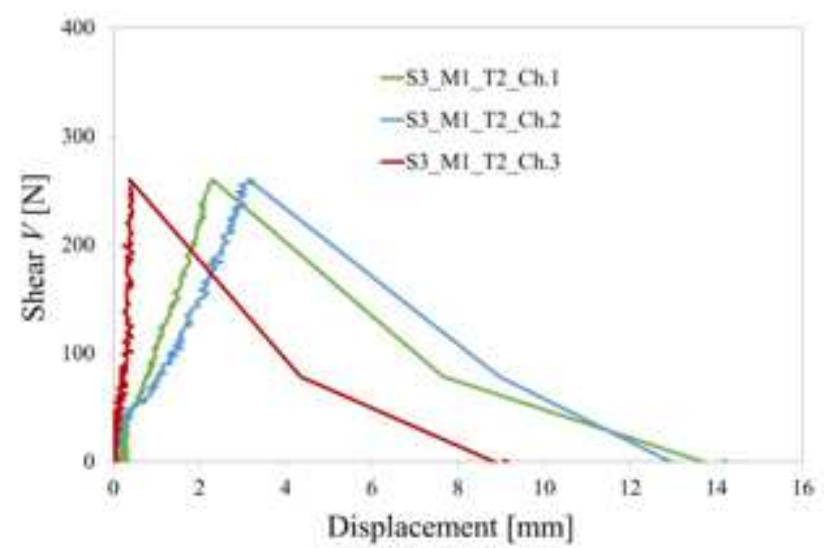

(d)

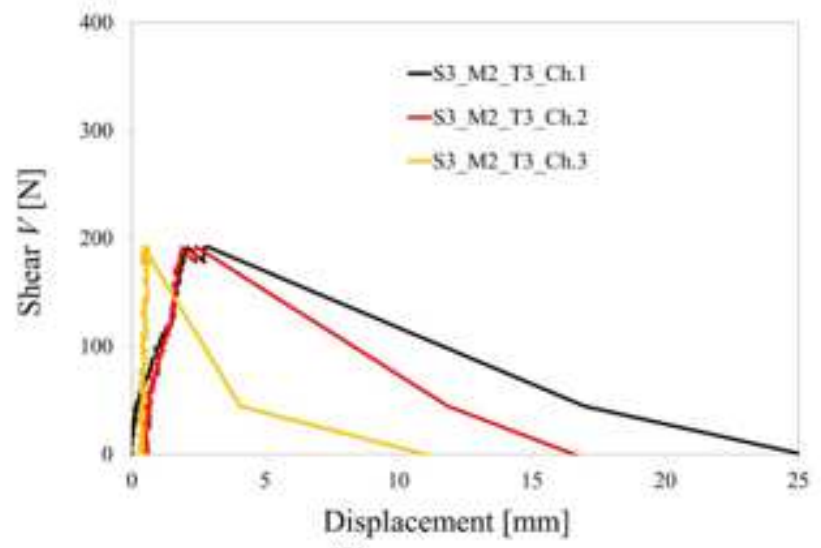

(f)

\section{Figure 9}

Load-displacement curves for S1 tests: (a) M1_T2 - M2_T2 and (b) M1_T1- M2_T3. Load-displacement curves for S2 and S3 tests and: (c,d) M1 and (e,f) M2 mortars. 


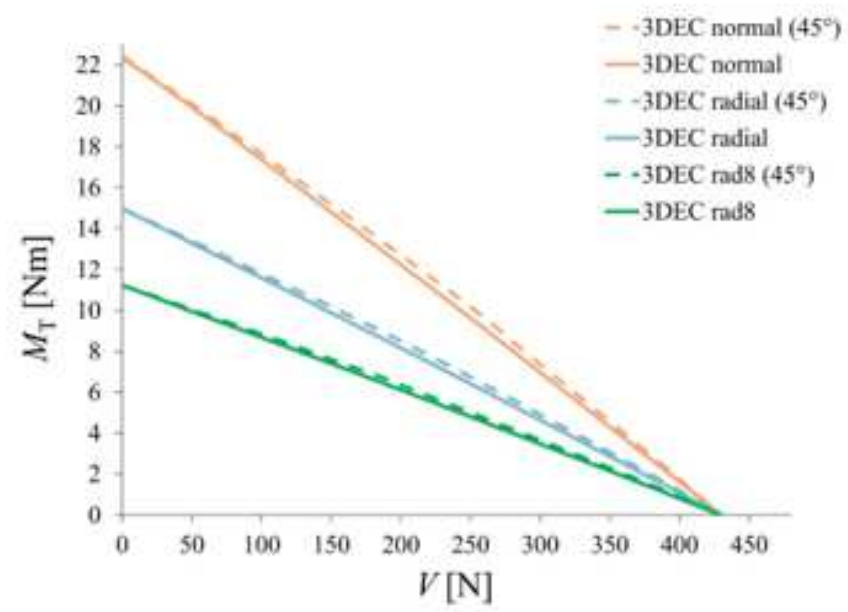

(a)

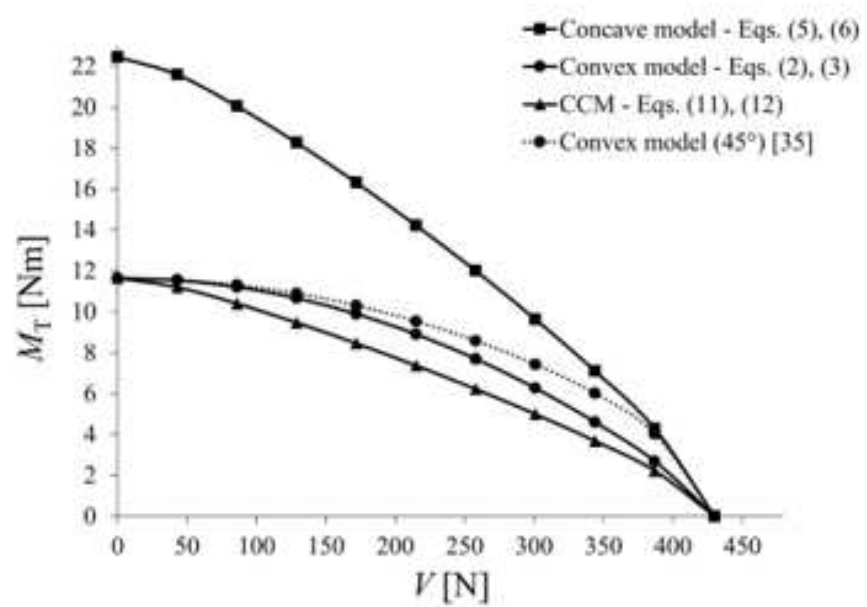

(b)

\section{Figure 10}

Numerical results for orthogonal and $45^{\circ}$ inclined shear forces and M1 mortar, obtained by the: (a) 3DEC model and (b) convex model.

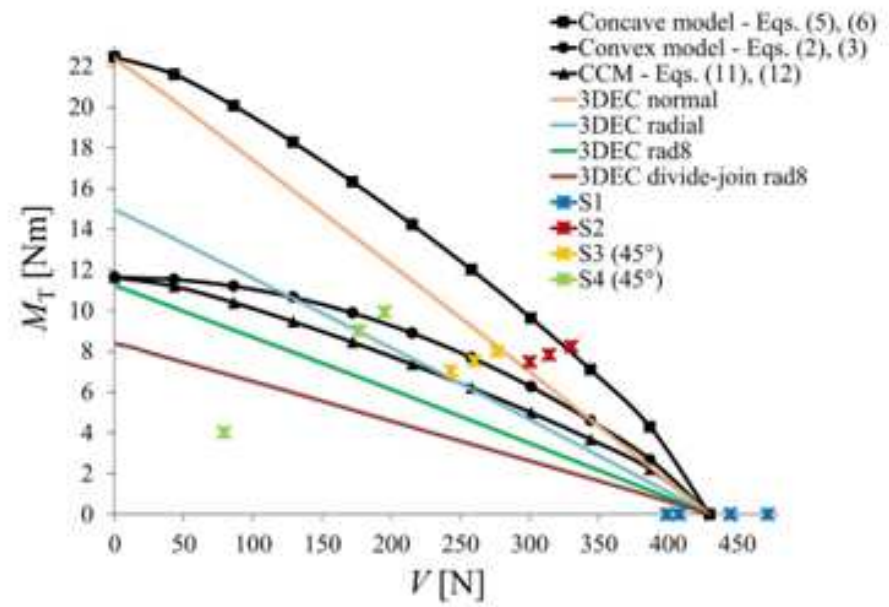

(a)

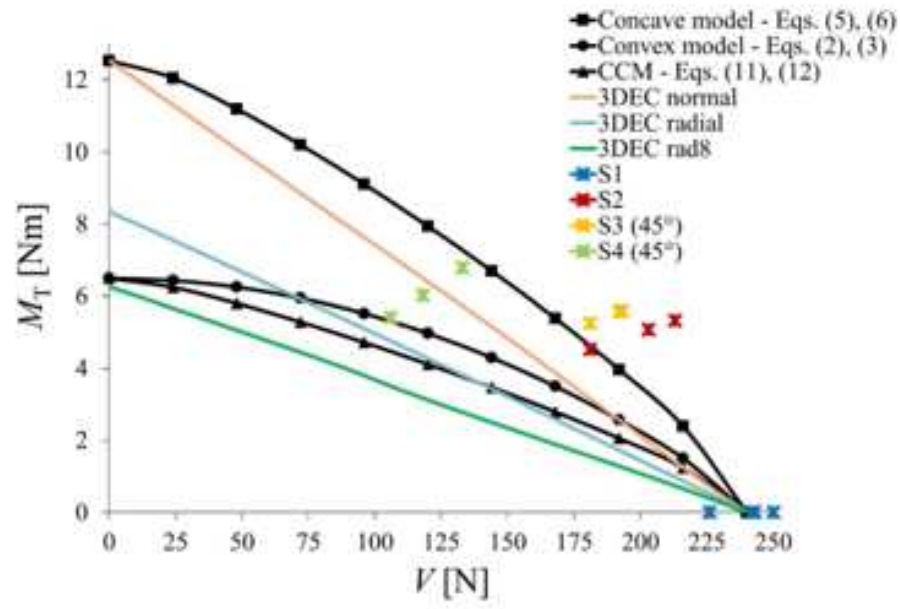

(b)

\section{Figure 11}

Numerical and experimental results for orthogonal shear forces and (a) M1 and (b) M2 mortars. 


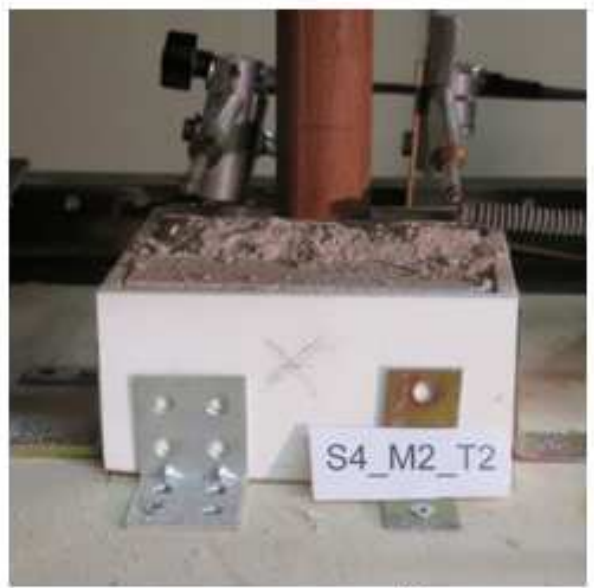

(a)

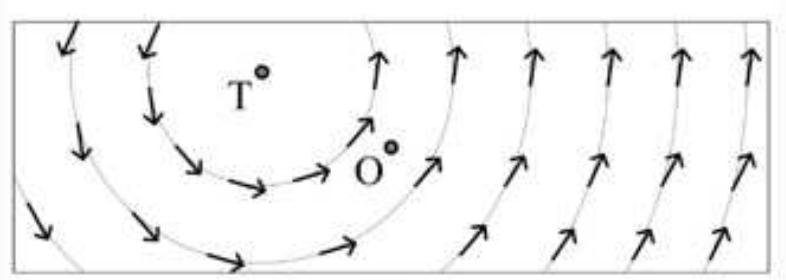

(b)

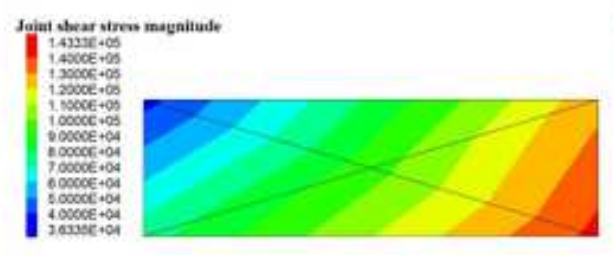

(c)

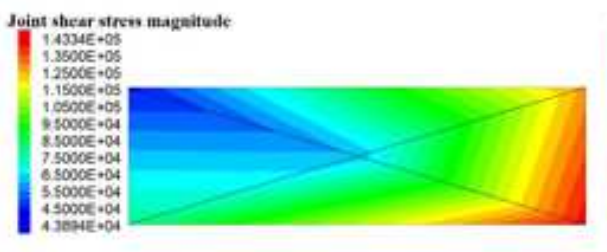

(d)

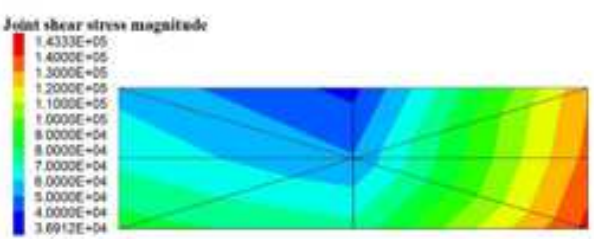

(e)

Figure 12

S4-M2 case. (a) Experimental cracking and shear stress distributions for the (b) convex model and the (ce) 3DEC face triangulation types. 